\title{
Characterizing nonnative plants in wetlands across the conterminous United States
}

\author{
Teresa K. Magee • Karen A. Blocksom • \\ Alan T. Herlihy • Amanda M. Nahlik
}

Received: 22 March 2018 / Accepted: 21 August 2018

(C) The Author(s) 2019

\begin{abstract}
Nonnative plants are widely recognized as stressors to wetlands and other ecosystems. They may compete with native plant species or communities and alter ecosystem properties, which can affect ecological condition, posing challenges to resource managers. As part of the United States Environmental Protection Agency's National Wetland Condition Assessment (NWCA), we characterized the status of nonnative plants in wetlands across the conterminous United States (US). Our primary goals were to (1) document the composition of nonnative taxa at 1138 NWCA sites sampled in 2011 and (2) estimate the areal extent of wetland under stress from nonnative plants within the NWCA 2011 sampled population of $\sim 25$ million ha of wetland (represented by 967 sampled probability sites and the NWCA survey design). A total of 443 unique
\end{abstract}

This article is part of the Topical Collection on Monitoring Wetlands on a Continental Scale: The Technical Basis for the National Wetland Condition Assessment

Electronic supplementary material The online version of this article (https://doi.org/10.1007/s10661-019-7317-3) contains supplementary material, which is available to authorized users.

T. K. Magee $(\bowtie) \cdot$ K. A. Blocksom • A. M. Nahlik

Office Research and Development, National Health and Environmental Effects Laboratory, Western Ecology Division, US Environmental Protection Agency, 200 SW 35th Street, Corvallis, OR 97333, USA

e-mail: magee.teresa@epa.gov

\section{A. T. Herlihy}

Department of Fisheries and Wildlife, Oregon State University, Corvallis, OR, USA nonnative taxa were observed, encompassing a species pool adapted to diverse ecological conditions. For individual sites, the number of nonnative taxa ranged from 0 to 29 , and total absolute cover of nonnatives ranged from 0 to $160 \%$. We devised the nonnative plant indicator (NNPI) as a categorical indicator of stress (low to very high) from the collective set of nonnative plant taxa occurring at a particular location, based on a decision matrix of exceedance values for nonnative richness, relative frequency, and relative cover. Wetland area of the sampled population occurring in each NNPI category was estimated at the scale of the conterminous US and within five large ecoregions and four broad wetland types. Potential stress from nonnative plants, as indicated by the NNPI category, was low for approximately $61 \%$ ( $\sim 15.3$ million ha), moderate for about $20 \%(\sim 5.2$ million ha), high for about $10 \%(\sim 2.48$ million ha), and very high for about $9 \%(\sim 2.2$ million ha) of the wetland area in the entire sampled population. Percent of wetland area with high and very high NNPI varied by ecoregional subpopulations: greater within interior and western ecoregions $(\sim 29$ to $87 \%)$ than within ecoregions in the eastern half of the nation $(\sim 11 \%)$. Among wetland type subpopulations, greater percent of wetland area with high and very high NNPI was observed for herbaceous vs. woody types and for inland vs. estuarine types. Estimates of wetland area by NNPI categories are expected to be useful to policy makers or resource managers for prioritizing management actions by identifying situations where stress from nonnative plants is most extensive. We also considered four exploratory analyses aimed at providing ecological 
information useful in interpreting NNPI extent results. We conducted three population-scale analyses examining ecoregional and wetland type population means for (1) the three NNPI metrics, (2) absolute cover of growth-habit groups of nonnative plants, and (3) metrics describing human-mediated disturbance. Finally, we examined ecological relationships with site-level NNPI status using a random forest (RF) analysis with NNPI as the response variable and predictor variables including ecoregion, wetland type, and a variety of characteristics describing natural vegetation structure, environment, and human-mediated disturbance.

Keywords Nonnative plant indicator (NNPI) · Potential ecological stress $\cdot$ Nonnative richness $\cdot$ Nonnative relative cover $\cdot$ Nonnative relative frequency $\cdot$ National Wetland Condition Assessment (NWCA) . Conterminous United States

\section{Introduction}

Nonnative plants are recognized as important indicators of stress to wetlands and other ecosystems (Mack and Kentula 2010; Magee et al. 2010; Schweiger et al. 2016). Their presence, richness, and abundance are often positively related to stressors of ecological condition caused by human-mediated disturbances (e.g., physical disturbances to vegetation or ground surface, changes in hydrology, nutrient inputs, changes in surrounding land use, and inadvertent introduction) (Lozon and MacIsaac 1997; Magee et al. 1999; Mack et al. 2000; Magee and Kentula 2005; Aguiar et al. 2007; Ringold et al. 2008; Jakubowski et al. 2014). Nonnative plants can also be direct stressors to ecological condition, altering native plant communities or ecosystem structure and processes (Vitousek et al. 1997; Dukes and Mooney 2004; Ehrenfeld 2010; D’Antonio and Flory 2017) and leading to losses of ecosystem services (Dukes and Mooney 2004; Hooper et al. 2005; Meyerson and Mooney 2007). Ecological impacts from nonnative species reflect changes to the biota, physical habitat, or processes of an ecosystem, with impact varying in type, direction, magnitude, and over space or time (Ricciardi et al. 2013). Reviews and meta-analysis from the literature indicate that nonnative plant species with potential for significant direct and indirect effects to the structure and function of ecosystems are common, and many of these taxa likely have yet to be recognized as harmful (Simberloff 2011;
Vilà et al. 2011). In addition, ecological impacts from nonnative species can occur at the levels of organism (e.g., fitness, mortality, growth), species population (e.g., abundance, genetics), plant community (e.g., species richness, species composition, structure), ecosystem (e.g., physical habitat, nutrient cycling), or region (Simberloff 2011; Vilà et al. 2011; Ricciardi et al. 2013).

For example, nonnative plants have been linked to (1) increased risk of local extinction or population declines for many rare, native plant species (Randall 1996; Lesica 1997; Seabloom et al. 2006; Gilbert and Levine 2013); (2) changes in species composition and vegetation structure within and among plant community types, and homogenization of local and regional floras (McKinney 2004; Rooney et al. 2004; Magee et al. 2008); (3) alteration of fire regimes (Dwire and Kauffman 2003; Brooks et al. 2004); (4) alteration of geomorphic and hydrologic processes (Rowantree 1991; Sala et al. 1996; Gebauer et al. 2016); and (5) alteration of carbon storage patterns (Farnsworth and Meyerson 2003; Bradley et al. 2006), nutrient cycling, and soil biota including microbial and mycorrhizal interactions with plants (Belnap and Phillips 2001; Ehrenfeld et al. 2001; Ehrenfeld 2003; Bowen et al. 2017). In addition, impact from nonnative plants to natural ecosystems may be exacerbated by ongoing global changes, with effects varying by region, ecosystem type, plant community type, and type of modification (e.g., climate, land use, and nutrient dynamics) (Dukes and Mooney 1999; Dwire et al. 2017; Liu et al. 2017).

As part of the 2011 National Wetland Condition Assessment (NWCA) (USEPA 2016c; Kentula and Paulsen 2019), conducted by the United States Environmental Protection Agency (USEPA) and its partners, we devised the nonnative plant indicator (NNPI) as an indicator of ecological stress to wetlands (USEPA 2016d). The vegetation data collected during the 2011 NWCA provide an unprecedented opportunity for characterizing nonnative plants in wetlands across the conterminous United States (US). In addition, the field protocols (USEPA 2011a) and the probability design (Olsen et al. 2019) underpinning the NWCA allow for detailed analyses across sampled sites, or, alternatively, for the expression of results as estimates of wetland area (i.e., extent estimates) within a sampled population, at national or regional scales (e.g., this paper, Lomnicky et al. 2019; Magee et al. 2019; Nahlik et al. 2019).

Directly measuring impacts to ecological condition is often not possible because the tools to do so are lacking or are prohibitive in cost and time, especially for large- 
scale studies. Consequently, stressor indicators have been widely used in large-scale ecological assessments and are typically based on straightforward, easy-tomeasure factors that reflect anthropogenic-driven properties related to declining ecological condition, but not necessarily implying direct or causal mechanisms for this decline (e.g., USEPA 2009; Mack and Kentula 2010; Sifneos et al. 2010; USEPA 2016a, b, d; Lomnicky et al. 2019). Similarly, the NNPI is not intended as a direct measure of ecological impact from nonnative plants. Rather, it is a categorical indicator based on a decision matrix, which considers all nonnative plants occurring at a given location using values for three metrics (richness, relative frequency, and relative cover of nonnative plant taxa) that each reflect different pathways of potential ecological impact (USEPA 2016d). In this paper, we give an overview of the NNPI, including the rationale for (1) considering all nonnatives occurring at a sampled location, (2) the selection of the three NNPI metrics, and (3) the assignment of metricspecific exceedance values for designating four categories (low to very high) of potential stress (hereafter, stressor-level categories).

Following the overview of the NNPI, the remainder of our paper focuses on the characterization of nonnative plant species in wetlands across the conterminous US using data from the 2011 NWCA. We, first, briefly characterize the study area by (1) defining the NWCA sampled population and reporting on estimated wetland area within ecoregional and wetland type subpopulations and (2) describing a variety of ecological attributes for each of these subpopulations. Second, we provide a summary of the individual nonnative species observed across sites sampled in 2011 to illustrate the scope of nonnative taxonomic diversity and abundance. Next, for the 2011 NWCA sampled population, we use the NNPI to estimate the area of wetland that falls into each of the NNPI stressor-level categories (low, moderate, high, very high) at the scale of the conterminous US and within major ecoregions and wetland types. Wetland area estimates within the different NNPI categories are expected to be useful to policy makers or resource managers in identifying situations where impact from nonnative plants is most extensive, and in informing and prioritizing management actions and future research. Finally, to aid in understanding the patterns described by the NNPI extent results, we also conduct and discuss a series of exploratory analyses. We consider how (1) the individual NNPI metrics, (2) growth-habit groups of nonnative plants, and (3) human-mediated disturbances might parallel population-scale ecoregional and wetland type patterns for NNPI extent results. We also explore how ecosystem and disturbance characteristics relate to site-scale NNPI stressor-level. These exploratory analyses help identify relationships that can be useful for hypothesis generation to inform future research.

\section{Description of the nonnative plant indicator}

\section{Rationale}

Stressor indicators for a large-scale study like the NWCA should be widely applicable across major ecoregions and wetland types. Nonnative plant species meet this criterion because they are not natural components in any ecosystem, are often associated with human-mediated disturbance, and, in many cases, are known to directly impact ecological condition. In addition, the identity and abundance of individual nonnative species or groups of nonnative plants can be readily described using species composition data that are commonly collected in field studies. Many nonnative taxa are known to be particularly invasive or associated with negative ecological impacts in a wide range of plant communities and environments (Randall et al. 2008; Magee et al. 2010; Barney et al. 2013; Blackburn et al. 2014). Rather than focusing only on those nonnative taxa currently documented as highly invasive or impactful, we chose an inclusive approach and based the NNPI on the entire complement of nonnative plants co-occurring at a given location. We did this to retain all useful signal in the nonnative plant data, because consideration of all nonnative species occurring together encompasses a variety of important ecological consequences.

For example, the type and level of impact from nonnatives is often dependent on species traits of invaders, traits of the recipient plant community, and the environmental context (e.g., habitat, biome or region, level of human-mediated disturbance) being invaded (Richardson and Pyšek 2006; Pyšek et al. 2012; Ricciardi et al. 2013). Individual nonnative plant taxa characterized by rapid spread across the landscape or dominance where they occur, or that act as ecosystem engineers (i.e., influence resource availability by altering biotic or abiotic elements of ecosystems), are likely to cause more immediate disruption to ecological condition than infrequent, low cover, or recently naturalized 
taxa (Richardson and Pyšek 2006; Baiser et al. 2008; Ehrenfeld 2010; Ricciardi et al. 2013). However, the sheer numbers of individual infrequent or low cover nonnative species that occur in natural landscapes (e.g., Seabloom et al. 2006; Pyšek et al. 2017) represent a likely invasion debt (i.e., a delay between introduction and extensive spread (Seabloom et al. 2006; Bennett et al. 2013; Beauvais et al. 2016)); that is, an undetermined subset of such nonnative taxa can be expected to undergo significant expansion in cover and distribution as they come into equilibrium with their introduced ranges, or as shifts in environmental conditions accompanying global change occur (Seabloom et al. 2006; Bennett et al. 2013). In addition, co-occurring multiple invaders can interact with one another and with native species via direct or indirect facilitative, neutral, or competitive pathways that may alter community composition and environmental conditions; potentially leading to nonnative accumulation or invasional meltdown, i.e., acceleration of nonnative establishment or ecological impact resulting in unrecoverable replacement of native communities (Simberloff 2006; Kuebbing et al. 2013; Kuebbing and Nuñez 2016). Taken together, the varied and interactive ecological effects of nonnative plants make it difficult to predict which nonnative species are likely to have the greatest impact in specific environments or plant communities.

In addition to incorporating all nonnative taxa cooccurring at a given location, we based the categorical NNPI on straightforward metrics that can be readily calculated from field observations to allow maximum applicability and ease of use. We selected three complementary metrics for use in the NNPI: (1) relative cover of nonnative species, (2) nonnative species richness, and (3) relative frequency of nonnative species. Formulas for their calculation are provided in Table 1. All three metrics consider all nonnative species at a location and each metric describes different possible avenues to ecological stress. Relative nonnative cover (0 to 100\%) reflects preemption of space and resources and is often associated with changes in plant community composition (species identity, richness, and abundance) and vegetation structure (horizontal or vertical), or with alteration of ecosystem processes (e.g., hydrology, nutrient cycling, fire regime). Greater nonnative richness (number of unique nonnative species) increases the risk that individual nonnative taxa are or may become invasive, or act as ecosystem engineers that negatively alter biotic or abiotic properties. Increasing relative nonnative
Table 1 Nonnative plant species metrics used in the nonnative plant indicator (NNPI)

\begin{tabular}{|c|c|}
\hline Metric name & Calculation $^{\mathrm{a}}$ \\
\hline $\begin{array}{l}\text { Nonnative relative } \\
\text { cover }\end{array}$ & 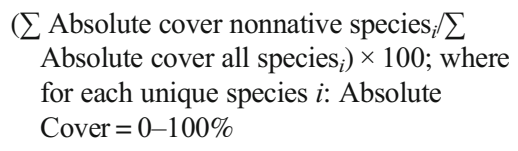 \\
\hline Nonnative richness & Number of unique nonnative species \\
\hline $\begin{array}{l}\text { Nonnative relative } \\
\text { frequency }\end{array}$ & $\begin{array}{l}\sum \text { Frequency nonnative } \text { species }_{i} / \sum \\
\text { Frequency all species } i) \times 100 ; \text { where for } \\
\text { each unique species } i \text { : } \\
\text { Frequency }=0-100 \% \text {, calculated as the } \\
\text { percent of Veg Plots in which it occurred. }\end{array}$ \\
\hline
\end{tabular}

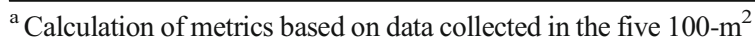
vegetation plots at each site (vegetation data collection described in the section "Plant data collection and trait assignment" under "Methods")

frequency (0 to 100\%) across a site reflects increasing numbers of foci from which nonnatives could compete with native species, expand in cover, or spread to new locations.

Relative frequency and relative cover of nonnatives at each site were selected as NNPI metrics, rather than absolute frequency and cover (i.e., the sum of frequencies or cover values across all individual nonnative species occurring at a location). Relative values normalize these two metrics to reflect the proportional influence of nonnatives within the varying vertical structure and species diversity represented by different vegetation types. For example, forested systems have more vertical layers than herbaceous systems (e.g., bottomland hardwood forest vs. seasonal wet prairie) and, therefore, greater total species cover. Likewise, some community types have greater species richness than others (e.g., mountain fen vs. Spartina alterniflora salt marsh) and, consequently, greater frequency of species occurrences at a site. In addition, some community types have varying amounts of nonvegetated area, such as bare ground or standing water, as part of their ecosystems. Thus, the same absolute (or total values) for nonnative cover or frequency could reflect very different proportions of the total vegetated component of the ecosystem under consideration.

The NNPI metrics (Table 1) were calculated using $\mathrm{R}$ code developed for the NWCA, and site values for each of the three metrics are included in the 2011 NWCA vegetation metric data (USEPA 2016m). See the "Plant data collection and trait assignment" section under "Methods" of this paper for description of the sampling 
and information gathering procedures for the data used in calculating the NNPI metrics. We evaluated signal:noise (S:N) for each of the NNPI metrics to ensure that, in addition to being ecologically appropriate, they would be effective at detecting signal in the data (USEPA 2016d). S:N is the ratio of variance in a metric across all sampled sites (signal) to the variance in the metric based on repeat sampling of individual sites (noise) (Kaufmann et al. 1999). Ninety-six probability sites, two per state, were identified in the survey design for repeat sampling during the field season (revisit sites) to gauge within sampling period data variability (noise). Metrics having S:N values greater than 2 are considered useful in making ecological distinctions (Stoddard et al. 2008; Magee et al. 2019). S:N exceeded this value for all the NNPI metrics: 5.9 for nonnative species richness, 23.9 for relative frequency of nonnative species, and 14.3 for relative cover of nonnative species.

\section{NNPI stressor-level categories}

The three NNPI metrics (nonnative relative cover, nonnative richness, and nonnative relative frequency, Table 1) were used together in a decision matrix to assign each sampled site to a stressor-level category (low, moderate, high, or very high) based on exceedance values (Table 2) for each metric. The NNPI status for each site was determined by the highest stressor-level category observed across the three NNPI metrics. This filter approach of using multiple metrics to designate the indicator status for individual sites was developed by Herlihy and others (e.g., Herlihy et al. 2008; Herlihy et al. 2019a), and we adapted this approach for the NNPI (USEPA 2016d). No established procedure existed to define boundaries for the stressor-level categories based on specific values of the NNPI metrics. Consequently, as a starting point, we defined exceedance values for the four stressor-level categories for each metric (Table 2) using best professional judgment based on our broad experience with numerous wetland community types and our perceptions of change in plant community composition and structure accompanying varying levels of nonnative cover, frequency, or richness. Major changes in plant community composition and structure are also often associated with impact to other biota and ecosystem properties (e.g., see literature cited in the "Introduction" and the "Rationale" sections). Exceedance values for the four stressor-levels were assigned to reflect the strong potential influence of nonnative relative cover, with the values for nonnative richness and nonnative relative frequency set to reflect these two metrics as additional sources of ecological stress. We recognize that other researchers might select different exceedance values for the four stressor-level categories; nevertheless, the exceedance values assigned for the three NNPI metrics were received favorably by NWCA partners (wetland scientists and managers) during discussions at analysis workshops and during extensive peer review of the NWCA Technical Report (USEPA 2016d).

As an example of how the exceedance values for the nonnative metrics (Table 2) are utilized, consider two hypothetical sites. Hypothetical site 1 has nonnative relative cover of $7 \%$, placing the site in the moderate stressor-level category. However, this site also has nonnative richness of 14 species and relative frequency of $32 \%$, which reflect the high stressor-level for both metrics; thus, the site would be assigned to the high NNPI category. Even though relative nonnative cover is not extensive at this hypothetical site, the number of individual nonnative species and their frequency of occurrence might indicate shifting community composition and strong risk for expansion of nonnative cover. Next, consider hypothetical site 2 with $80 \%$ nonnative relative cover that places the site in the very high stressor-level category, nonnative richness of 1 indicating the low

Table 2 Stressor-level category exceedance thresholds for each of the three metrics informing the nonnative plant indicator (NNPI)

\begin{tabular}{llll}
\hline Stressor-level category* & Relative cover nonnative species & Richness nonnative species & Relative frequency nonnative species \\
\hline Low & $\leq 1$ & $\leq 5$ & $\leq 10$ \\
Moderate & $>1-15$ & $>5-10$ & $>10-30$ \\
High & $>15-40$ & $>10-15$ & $>30-60$ \\
Very high & $>40$ & $>15$ & $>60$ \\
\hline
\end{tabular}

*Exceedance of a threshold value for a particular stressor-level category for any of the three component metrics moves the NNPI to the next higher stress level 
stressor-level category, and nonnative relative frequency of 59\% that indicates high stressor-level. Here, the hypothetical site NNPI would fall into the very high category. Even though there is only one nonnative species present at the site, it occupies $80 \%$ of the total vegetation cover and nearly $60 \%$ of all species occurrences across the sampled area of the vegetation plots are nonnative.

\section{Methods}

Survey design and data use

The NWCA probability-based survey design is detailed in Olsen et al. (2019). Sites were identified using a spatially balanced generalized random tessellation stratified design for an area resource (Stevens Jr. and Olsen 1999, 2004) and the US Fish \& Wildlife Service's National Wetland Status and Trends digital sample frame for wetlands (Dahl and Bergeson 2009; Dahl 2011). The target wetland population for the NWCA encompassed tidal and nontidal systems, across the conterminous US, that had rooted vegetation and, when present, open water less than $1 \mathrm{~m}$ deep (Table 3). Each selected sample point (i.e., coordinates of site location) received a weight reflecting the wetland area within the target population represented by that point (Olsen et al. 2019). Sample weights for probability sites were used to (1) estimate wetland area with particular characteristics across the nation, regionally, or by wetland type; and (2) to calculate population-weighted means for specific vegetation attributes and environmental metrics (Diaz-
Ramos et al. 1996). Area estimates and population means are calculated with known margins of error (two-sided 95\% confidence interval (CI)) based on a local neighborhood variance estimate (Stevens Jr. and Olsen 2003). Site selection, weight assignment, wetland area estimation, and calculation of population-weighted means for specific metrics were completed using $\mathrm{R}$ statistical software (R_Core_Team 2015, 2017) and the 'spsurvey' $\mathrm{R}$ contributed package (Kincaid and Olsen Jr. 2015).

The inference (or sampled) population for the NWCA was described by 967 probability sites that were identified in the survey design and sampled in 2011 (Fig. 1, Table 4). Only data from these 967 probability sites were used to make wetland area estimates for the sampled wetland population or subpopulations and to calculate population-weighted means for specific metrics describing vegetation attributes or environmental conditions for the sampled population or subpopulations.

An additional 171 sites were selected outside of the NWCA survey design (Fig. 1) and were used only in two analyses that did not involve extrapolation of results across the areal extent of the NWCA sampled population. This set of 'other' sites included 21 that supported state-level studies that were part of the NWCA, but could be used only for site-level analyses because their locations were selected outside the NWCA probability design (USEPA 2016d). The remaining 150 'other' sites were handpicked in an effort to represent locations with limited anthropogenic disturbance; however, these sites actually spanned a range of disturbance levels with only about half meeting criteria for least-disturbed reference

Table 3 Definition of NWCA target population and description of the NWCA aggregated wetland types used in analysis

\begin{tabular}{|c|c|c|c|}
\hline \multicolumn{2}{|l|}{ Target population } & \multirow{2}{*}{$\begin{array}{l}\text { NWCA aggregated wetland type } \\
\text { EH- estuarine intertidal herbaceous }\end{array}$} & \multirow{2}{*}{$\begin{array}{l}\text { Description } \\
\begin{array}{c}\text { Estuarine or intertidal } \\
\text { emergent wetlands }\end{array}\end{array}$} \\
\hline \multirow{4}{*}{$\begin{array}{l}\text { Wetlands across conterminous US } \\
\text { representing tidal and nontidal } \\
\text { systems with rooted vegetation } \\
\text { and, when present, } \\
\text { open water } \leq 1 \mathrm{~m} \text { deep }\end{array}$} & \multirow[t]{2}{*}{ Estuarine intertidal } & & \\
\hline & & EW - estuarine intertidal woody & $\begin{array}{l}\text { Estuarine or intertidal shrub } \\
\text { and forested wetlands }\end{array}$ \\
\hline & \multirow[t]{2}{*}{ Inland } & $\begin{array}{l}\text { PRLH-palustrine, riverine, } \\
\text { and lacustrine herbaceous }\end{array}$ & $\begin{array}{l}\text { Emergent, ponded, } \\
\text { or previously farmed } \\
\text { wetlands in palustrine, } \\
\text { shallow riverine, or shallow } \\
\text { lacustrine littoral settings }\end{array}$ \\
\hline & & $\begin{array}{l}\text { PRLW-palustrine, riverine, } \\
\text { and lacustrine woody }\end{array}$ & $\begin{array}{l}\text { Forest- or shrub-dominated } \\
\text { wetlands in palustrine, } \\
\text { shallow riverine, or shallow } \\
\text { lacustrine littoral settings }\end{array}$ \\
\hline
\end{tabular}




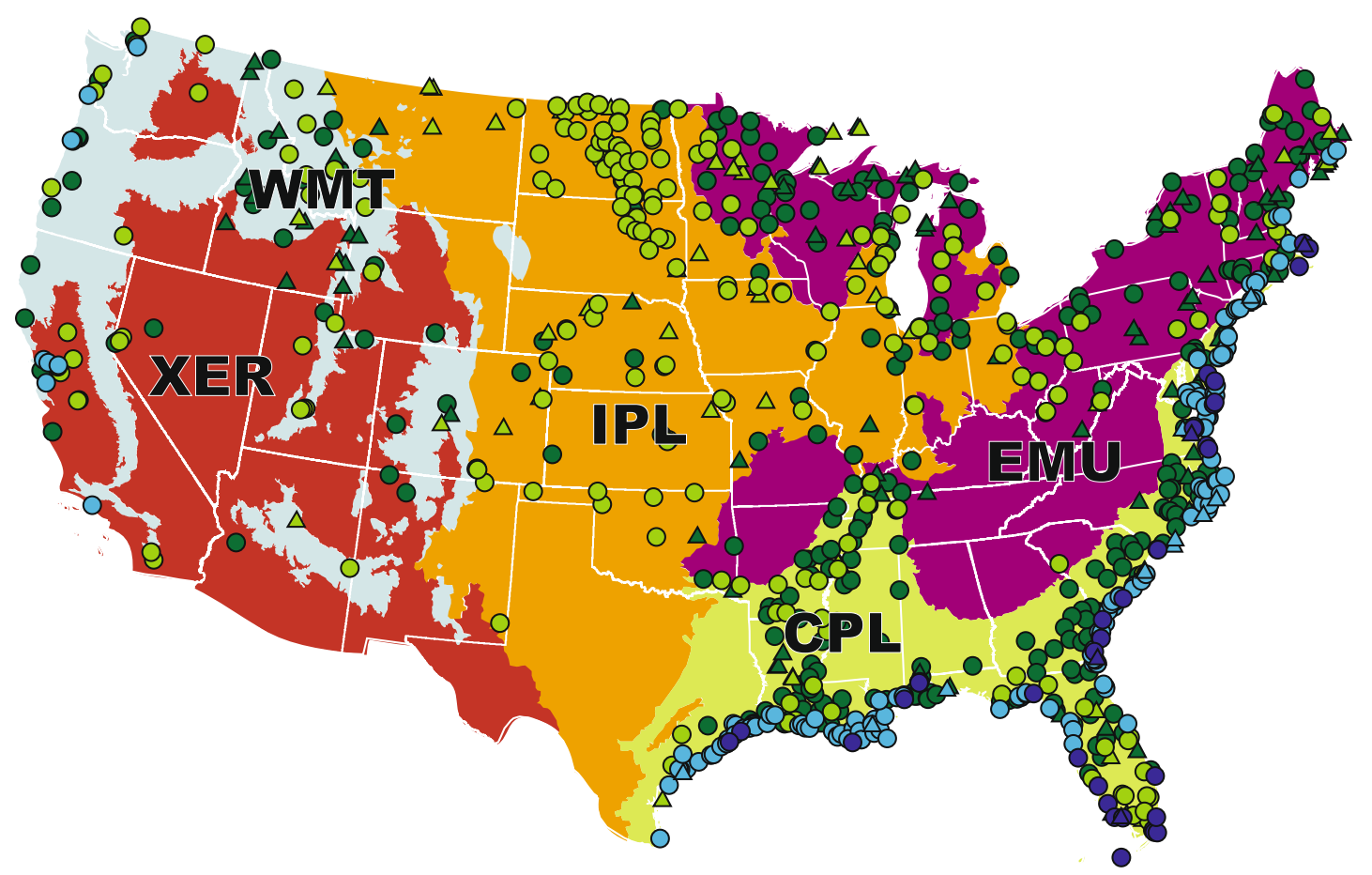

\section{NWCA Aggregated Ecoregions}

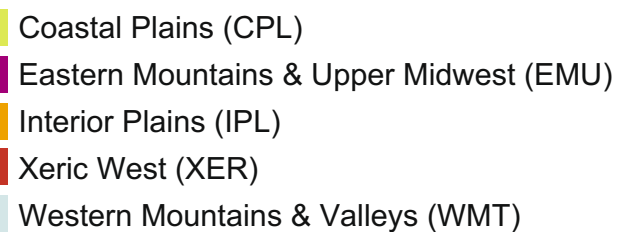

Coastal Plains (CPL)

Eastern Mountains \& Upper Midwest (EMU)

Interior Plains (IPL)

Xeric West (XER)

Western Mountains \& Valleys (WMT)

\author{
NWCA 2011 Sites Sampled \\ ( $=$ Probability Sites $/ \mathbf{\Delta}=$ Other Sites) \\ $\mathrm{O} / \triangle$ Estuarine Herbaceous (EH) \\ O/A Estuarine Woody (EW) \\ $\mathrm{O} / \triangle$ Palustrine, Riverine, Lacustrine Herbaceous (PRLH) \\ O/A Palustrine, Riverine, Lacustrine Woody (PRLW)
}

Fig. 1 Locations of 1138 sites sampled in the 2011 National Wetland Condition Assessment (NWCA) and their distribution across five NWCA ecoregions (see Table 4). See Table 3 for definitions of the estuarine (EH and EW) and inland (PRLH and PRLW) wetland types

sites (Herlihy et al. 2019a). We used data from all 1138 sampled sites (probability + other sites) to maximize sample sizes for two site-scale analyses: (1) summarizing the occurrence and abundance of all individual nonnative species observed and (2) examining sitescale relationships of ecological predictors to NNPI stressor-level categories. Sample weights could not be used when all 1138 sites were considered; thus, results of these two analyses reflect site-specific patterns that should not be inferred across the entire sampled population.

All 1138 sampled sites were classified into five aggregated ecoregions (Fig. 1, hereafter ecoregions) and four broad aggregated wetland types (Table 3, Fig. 1; hereafter, wetland types) to minimize within-group variation and still maintain sufficient sample sizes for analysis (see, Herlihy et al. 2019a; Magee et al. 2019). Table 2 lists the distribution of the 1138 sites sampled across the conterminous US, by ecoregion and wetland type. Ecoregion and wetland type designations and a variety of NWCA site descriptors (e.g., site identifiers, location, sample weights) used to support analyses are included in NWCA site information data (USEPA 20161).

Plant data collection and trait assignment

Field and laboratory methods for collecting data on vegetation for the 2011 NWCA are outlined here and detailed elsewhere (USEPA 2011a, b; Magee et al. 2019). Vegetation sampling methods were widely reviewed, tested, and vetted during the development of the NWCA sampling protocols described in the NWCA Field Operations Manual (USEPA 2011a). The 53 NWCA field crews received intensive training in sampling protocols prior to the field season and had access 
Table 4 Distribution of the 1138 sites sampled in the 2011 NWCA. 'Other' sites were selected outside NWCA design. 'Probability' sites are from survey design. 'Wetland area' is area and $95 \%$ CIs represented by the probability sites

\begin{tabular}{|c|c|c|c|c|c|c|}
\hline NWCA popı & ition & Total sites & Other sites & Probability & Wetland area $\left(10^{6} \mathrm{ha}\right)$ & $\%$ sampled \\
\hline Conterminou & US & & & & & \\
\hline & All sites ${ }^{\mathrm{a}}$ & 1138 & 171 & 967 & $25.15 \pm 2.13$ & 100 \\
\hline Ecoregion & & & & & & \\
\hline CPL & Coastal Plain & 567 & 54 & 513 & $12.5 \pm 1.51$ & 50 \\
\hline EMU & $\begin{array}{l}\text { Eastern Mountains and } \\
\text { Upper Midwest }\end{array}$ & 214 & 62 & 152 & $8.08 \pm 1.26$ & 32 \\
\hline IPL & Interior Plains & 190 & 34 & 156 & $3.10 \pm 0.74$ & 12 \\
\hline XER & Xeric West & 62 & 3 & 59 & $1.08 \pm 0.31$ & 4 \\
\hline WMT & Western Mountains and Valleys & 105 & 18 & 87 & $0.40 \pm 0.11$ & 2 \\
\hline Wetland type & & & & & & \\
\hline EH & Estuarine intertidal herbaceous & 272 & 14 & 258 & $2.01 \pm 0.42$ & 8 \\
\hline EW & Estuarine intertidal woody & 73 & 4 & 69 & $0.20 \pm 0.13$ & 1 \\
\hline PRLH & Inland herbaceous & 358 & 56 & 302 & $5.70 \pm 0.81$ & 23 \\
\hline PRLW & Inland woody & 435 & 97 & 338 & $17.43 \pm 1.91$ & 69 \\
\hline
\end{tabular}

\footnotetext{
${ }^{a}$ Totals across subpopulations under ecoregions and wetland type equal the all sites totals. See Fig. 1 for NWCA ecoregion boundaries and
} Table 3 for aggregated wetland type definitions

to expert and logistic support throughout the field season (McCauley et al. 2019). Each field crew included a two-member vegetation team, at least one of whom had strong expertise in the flora of the state or region where the crew worked. Plant species data were collected during the peak growing season (determined regionally as the time period when most plants were in flower or fruit) to optimize species identification and characterization of species abundance. At each site, plant data were gathered from five $100-\mathrm{m}^{2}$ Vegetation (Veg) Plots that were systematically placed within a typically circular, 0.5 ha assessment area (AA). Alternate configurations for AA shape and other systematic Veg Plot layouts were used only when necessary, as determined by rules related to specific site conditions (USEPA 2011a).

All vascular plant taxa occurring in each Veg Plot were identified to the lowest taxonomic level possible (typically species or lower, but occasionally genus or family). Specimens were collected for plant taxa that could not be identified in the field, and later identified in the lab by regionally expert botanists. Percent absolute cover for each taxon (0 to 100\%) in each Veg Plot was visually estimated across the entire $100-\mathrm{m}^{2}$ area (USEPA 2011a), and cover data for the observed taxa can be found in USEPA (2016i). Taxonomy for all observed vascular plant taxa was standardized (USEPA 2016d) to PLANTS Database nomenclature (USDA-NRCS 2014).
State-level native status categories (USEPA 2016d; Magee et al. 2019) were designated for the nearly 13,000 taxon-state pairs (trait data: USEPA 2016h) observed across the 1138 NWCA sites sampled across the conterminous US. A body of evidence approach was used to identify the state-level native status of each observed taxon. Native status categories (Table 5 and listed in italics below) for the taxon-state pairs were assigned based on review of numerous taxonomic and ecological sources $(n \sim 85)$, including state and regional floras and checklists, and state and national floristic databases and distribution maps (USEPA 2016d). For species with complex origins or species for which limited information was available, consultation with the PLANTS Database (USDA-NRCS 2013) nomenclatural team helped inform native status determinations. Taxa recognized as indigenous to a certain state were identified as Native. Alien plants were designated as those that were either (1) Introduced to the conterminous US, or (2) Adventive, that is, native to some parts of the conterminous US but introduced to the location of occurrence at a particular NWCA site. Cryptogenic species (Carlton 1996; Galatowitsch et al. 1999) include taxa with both introduced (often aggressive) and native (generally less prevalent) genotypes, varieties, or subspecies. Many cryptogenic taxa found in wetlands have strongly invasive components (e.g., Phalaris arundinacea 
Table 5 Definition of state-level native status designations for NWCA taxa

Native status designations

Native: indigenous to specific states in the conterminous US

Nonnative: alien + cryptogenic

Alien: introduced + adventive

Introduced: indigenous outside of, and not native in, the conterminous US

Adventive: native to some areas of the US, but introduced in the location of occurrence

Cryptogenic: both native and introduced genotypes, varieties, or subspecies

Undetermined: growth habits, families, genera with native and alien species

(Brodersen et al. 2008; Jakubowski et al. 2014), Phragmites australis (Simberloff et al. 2012; Allen et al. 2017a, b; Bowen et al. 2017)). Thus, we grouped cryptogenic species with alien taxa as Nonnatives (Table 5) for purposes of our analysis. Taxa identified only to growth habit or family, or to genera with native and alien species, were given a native status of Undetermined.

Species growth-habit designations were obtained from the PLANTS database (USDA-NRCS 2012) and summarized (USEPA 2016d) to assign standardized growth habit to the individual vascular taxa observed in the NWCA (trait data: USEPA 2016j). These standardized growth-habit categories were further consolidated to forb, graminoid, vine, shrub, and tree. Regionally specific wetland indicator status $(\mathrm{OBL}$ - obligate, FACW - facultative wetland, FAC - facultative, or FACU - facultative upland) for each observed NWCA species (trait data: USEPA 2016k) was based on the National Wetland Plant List (NWPL) and associated Wetland Regions defined by US Army Corps of Engineers (USACE 2014). Upland (UPL) status was assigned to NWCA taxon-region pairs not listed in the NWPL. In addition, a numeric value was assigned to each wetland indicator status (i.e., $\mathrm{OBL}=1, \mathrm{FACW}=2$, $\mathrm{FAC}=3, \mathrm{FACU}=4$, and $\mathrm{UPL}=5$ ).

Characterization of the 2011 NWCA sampled population

The extent of the NWCA sampled population was characterized using sample weights for the individual sampled probability sites $(n=967)$ to estimate the area by wetland type within ecoregions. In addition, population-weighted means $( \pm 95 \% \mathrm{CI})$ were calculated for several native vegetation and environmental attributes, using values observed at the 967 sampled probability sites and the site sample weights, to provide a general description of ecoregion and wetland type subpopulations. Attributes of native vegetation included native species richness (number of unique native species) and the absolute percent cover for native plants by growth habit (forb, graminoid, shrub, tree, and vine). Absolute cover was used to represent the area at each sampled site influenced by each growthhabit group. A wetland index (WI) based on species composition was calculated for each site. The WI is a cover-weighted wetland affinity score based on all plant species observed at a site: the sum of the numeric value (1 to 5) representing wetland indicator status (OBL to UPL) for each species weighted by its absolute cover, divided by the sum of absolute cover values for all observed species (Wentworth et al. 1988). A WI with a value of 1 indicates entirely obligate wetland vegetation and a value of 5 indicates entirely upland vegetation (Wentworth et al. 1988). Because the WI is correlated with moisture gradients, it provides a rough description of relative hydric conditions (Wentworth et al. 1988; Schweiger et al. 2016). Native vegetation attributes and the wetland index were based on data collected in the Veg Plots at each sampled site and are included in or calculated from the 2011 NWCA vegetation metric database (USEPA 2016d, m). Environmental characteristics included percent cover of bareground observed across the Veg Plots at each sampled site (USEPA 2016m), mean annual precipitation (30-year average within 1000-m radius surrounding the AA center for each site) from the PRISM database (Daly et al. 2008; PRISM Climate Group 2013), and maximum elevation (within 200-m radius surrounding the AA center) based on NHDPlusV2 NEDSnapshot (USGS 2006; McKay et al. 2012). Precipitation and elevation metric values for NWCA sites are available from the NWCA land use data set (USEPA 2016g).

Characterization of the complement of observed nonnative plant taxa

We examined the distribution of the 443 unique nonnative taxa observed across all NWCA sampled sites $(n=$ 
1138) to document the scope of nonnative taxonomic diversity and abundance patterns. To do this, we constructed an ordered table (Supplement 1) listing each nonnative species by (1) growth-habit group (forb, graminoid, vine, and shrub/tree), (2) total number of site occurrences, (3) mean importance $((\%$ frequency $+\%$ cover)/2) at sites of occurrence, and (4) number of site occurrences in each of the five NWCA ecoregions.

\section{Estimates of wetland area by NNPI stressor-level}

The NNPI status and the sample weight from the 2011 NWCA survey for each sampled probability site $(n=$ 967) were used to estimate the wetland area with low, moderate, high, or very high stressor-level categories for the NWCA sampled population. Area estimates with 95\% CIs for NNPI stressor-level categories were made nationally, by wetland type, and by ecoregion.

\section{Exploratory analyses}

\section{Population means for NNPI metrics and growth-habit groups for nonnatives}

Population-weighted means ( $\pm 95 \% \mathrm{CI})$, based on observed values at the 967 probability sites and the site sample weights, were calculated for the three NNPI metrics (Table 1: nonnative richness, nonnative relative frequency, and nonnative relative cover) for ecoregion and wetland type subpopulations. We also examined population-weighted means for absolute percent cover of nonnatives within four growth-habit types (forb, graminoid, vine, trees/shrubs) at the scale of the conterminous US, and for ecoregion and wetland type subpopulations to evaluate how nonnative abundance might vary by growth habit. Nonnative trees and shrubs were combined into one group because many individual nonnative woody species occur in both shrub and tree growth habits, and because mean cover values for nonnatives classed only as shrubs were often small. For the growth-habit metrics, we examined absolute percent cover, rather than relative cover, to distinguish the spatial area influenced by each growth-habit group at each sampled site. Differences in population-weighted means between different variables were characterized based on nonoverlapping 95\% CIs.

\section{Characterization of human-mediated disturbance}

We evaluated population-weighted means $( \pm 95 \% \mathrm{CI})$, calculated using the observed values at the 967 probability sites and the site sample weights, for three attributes of human-mediated disturbance for ecoregions and wetland types. Indicators of human-mediated disturbance included a site-scale index and two landscape metrics (percent agricultural and percent developed land use). The site-level disturbance index summarizes the overall human-mediated disturbance observed on-theground at each site at the date of sampling, and was based on combination of eight indices, which describe several disturbance types defined in USEPA (2016d). These eight disturbance indices were derived from approximately 85 disturbance descriptors that were evaluated at each sampled site within the AA and its associated $100-\mathrm{m}$ radius buffer. Five of these indices summarized categories of physical disturbances (agriculture, residential/urban, industrial, hydrologic, and habitat modifications) in the AA and buffer area, two described the level of hydrologic alterations in the AA (USEPA 2016d), and one described heavy metal concentrations in the soil of the AA (Nahlik et al. 2019). Data for these eight indices are available in USEPA (2016f). To create the overall site-level disturbance index, we standardized values for each specific disturbance index across all sampled sites to a 0 to 10 continuous scale using the formula: ((observed value - minimum)/(maximum minimum $\times 10$ ), then summed these scores and multiplied this total by $10 / 8$ to obtain an overall site-level disturbance index value with a possible range from 0 to 100. Percent agricultural and developed land use coverages (within a 1000-m radius surrounding the AA center) were based on the 2006 National Land Cover Database (Fry et al. 2011) and are available from the NWCA land use data set (USEPA 2016g).

\section{Ecological relationships to site-level NNPI status}

Random forest classification (RF) analysis (Liaw and Wiener 2002; Liaw and Wiener 2015) was used (1) to determine if the vegetation, environmental, and humanmediated disturbance metrics described in the previous sections, along with ecoregion and wetland type, might usefully predict NNPI stressor-level category; and (2) to examine the relative importance of each predictor variable in the resulting model. Complex ecological processes often involve multiple interactions and nonlinear 
relationships among variables, and RF analysis performs well with data that reflect these properties (De'ath and Fabricius 2000; Cutler et al. 2007; Fox et al. 2017). RF reduces model variance and increases prediction accuracy by building numerous decisions trees from bootstrap samples of a data set and averaging the predictions made by each tree in the forest (Cutler et al. 2007; Fox et al. 2017). In addition, $\mathrm{RF}$ is robust to the inclusion of variables with low importance (Fox et al. 2017), and variable importance is distributed across all the predictor variables in RF models, preventing elimination of ecologically important predictors of the response that might be correlated with other predictors (Cutler et al. 2007; Fox et al. 2017). We constructed our RF model for predicting NNPI status using the R computing language (R_Core_Team 2015, 2017) and the 'randomForest' package ver. 4.6-12 (Liaw and Wiener 2002, 2015) with the following options: (1) number of trees used to build the model (ntree) set to 1000 and (2) number of variables randomly selected at each tree node (mtry) set to the package default mtry $=\sqrt{p}$, where $p$ is the number of predictor variables. NWCA sample weights were not considered in the analysis.

Although the NNPI is normally categorized into four stressor-levels (low, moderate, high, very high), for the $\mathrm{RF}$ analysis, these were aggregated into two combined stressor-levels (low-moderate vs. high-very high). Thus, the response for the RF classification is the categorization of all NWCA sampled wetland sites $(n=1138$, probability + other sites) as having either low-moderate or highvery high NNPI stressor-level. We elected to use these combined stressor levels because some wetland type or ecoregion subpopulations had comparatively few sampled sites with high or very high NNPI. Also, preliminary $\mathrm{RF}$ analysis results showed greater percent correct classification of sites for the two-combined vs. four separate NNPI stressor-levels. Because the response data were unbalanced, with $72 \%$ of sampled sites having LM $(n=824)$ and $28 \%$ of sampled sites with high-very high $(n=314)$ NNPI status, we used a downsampling approach recommended by Fox et al. (2017) to improve predictive accuracy of the minority class. Each tree in the forest was built by drawing a bootstrap sample with the same number of cases from the low-moderate and highvery high categories based on the size of the minority class ( $n=314$ sites).

Procedures included in 'randomForest' were used to assess model performance based on correct classification of the response for each site (Liaw and Wiener 2002, 2015), in our case, low-moderate vs. high-very high stressor-level. The randomForest package uses the portion of data not contained in the bootstrap sample for an individual tree (the out-of-bag (OOB) data), to predict the response of site $i$ for each modeled tree in the forest where $i$ is OOB and takes the majority vote as the predicted stressor-level and the proportion of high-very high votes as the OOB predicted probability for that site (Cutler et al. 2007; Fox et al. 2017). Measures of model performance computed using these OOB predictions are essentially cross-validated accuracy estimates (Cutler et al. 2007; Fox et al. 2017). Here, we consider the following performance measures: percent of all sites $(n=1138)$ correctly classified, percent of high-very high NNPI sites correctly classified, and percent of low-moderate NNPI sites correctly classified.

To determine which predictors were most important in identifying when the NNPI was likely to be high-very high, variable importance was calculated as mean decrease in accuracy, and the results were plotted to show relative importance of the variables (using the 'varImpPlot' function in the 'randomForest' package, Liaw and Wiener 2015). Mean decrease in accuracy is a permutation measure of variable importance calculated using only $\mathrm{OOB}$ data, and higher values indicate greater importance of a predictor variable to the classification (Cutler et al. 2007). We also generated partial dependence plots for each predictor variable in the RF model, using the 'partialPlot' function in the 'randomForest' package (Liaw and Wiener 2015), to examine the influence of individual predictors. Partial dependence plots depict the probability of the high-very high stressorlevel for the NNPI as a function of a specific predictor variable after averaging out the effects of the other predictor variables in the model (Liaw and Wiener 2015).

\section{Results and discussion}

First, we define and briefly characterize the NWCA sampled population to which results of this study apply. Second, the complement of individual nonnative plant taxa observed across sites sampled in 2011 is described to illustrate the scope of nonnative taxonomic diversity and abundance. Next, we estimate the wetland area in the 2011 NWCA sampled population that falls into each of the four NNPI stressor-levels across the conterminous US and within major ecoregions and wetland types. To aid in understanding the patterns described by the NNPI 
extent results, we conduct a series of four exploratory analyses. We evaluate how population-scale means for (1) the three individual NNPI metrics, (2) growth-habit groups of nonnative plants, and (3) human-mediated disturbances might parallel NNPI stressor-level extent results. The final exploratory analysis uses RF classification to examine relationships of potentially interacting ecological attributes and disturbance characteristics to site-level NNPI status.

Most of the analyses presented in this paper are based on the 967 probability sites and use sample weights to reflect population-scale patterns (see "Methods" for details). All figures and tables reporting population-scale results include 95\% CIs. Differences in wetland area, or in metric or attribute means, are recognized based on nonoverlapping CIs (USEPA 2016c, d). Although nonoverlapping CIs provide quantification of the level of confidence in the difference for a certain comparison, they do not necessarily equate to significant difference because multiple individual comparisons are considered in these analyses. Note, confidence intervals will tend to be larger where sample sizes are smaller (USEPA 2016c).

For the characterization of the complement of individual nonnative taxa observed in 2011 and the exploratory RF analysis, sample weights were not used because these analyses considered all sampled sites $(n=$ 1138), rather than only probability sites. Thus, results for these two analyses reflect the specific sites sampled and should not be extrapolated to the entire NWCA sampled population.

\section{Characterization of the 2011 NWCA sampled} population

The wetland area of the 2011 NWCA target population across the conterminous US was estimated at approximately 38 million ha; however, approximately one third of this area was represented by sites selected by the design, but not sampled due to denial of access by land owners, inaccessibility, or safety constraints (Olsen et al. 2019). Consequently, the NWCA sampled population, characterized by the 967 sampled probability sites, encompassed a subset of the NWCA target population area and represents approximately 25 million ha of wetland (USEPA 2016d). In the sampled population, both area and wetland types are unequally distributed across the five major ecoregions (Fig. 2, Supplement 2 (S2)-Table A, and Table 4). This unequal distribution of wetland area and types was driven, in part, by the survey design, which accounted for the spatial distribution of wetlands across the US, and in part, because access issues precluded sampling some sites identified in the survey design (Olsen et al. 2019). As a result, the percent of the NWCA target population area accounted for in the sampled population was less in some ecoregions (Xeric West, Western Mountains and Valleys) and some wetland types (EW-estuarine woody, PRLH - inland herbaceous) than others (Table 6). Nonetheless, the scale of the overall sampled population and subpopulations, represented by the probabilitybased 2011 NWCA data set, is unique in areal extent and proportion of the wetland resource described with ecological data.

To provide a general description of the NWCA ecoregion and NWCA wetland type subpopulations, we looked at population-weighted means for several native vegetation attributes and environmental characteristics (Table 7). Mean native species richness varied ecoregionally (Table 7): greatest in the Eastern Mountains and Upper Midwest (46), followed by the Western Mountains and Valleys (35), somewhat less in the Interior Plains (29) and Coastal Plains (27), and least in the Xeric West (10). Mean native richness also varied by wetland type (PRLW-inland woody $=39, \mathrm{PRLH}=24$, $\mathrm{EW}=13, \mathrm{EH}-$ estuarine herbaceous $=4$ ), and was greater for woody than herbaceous types and greater in inland than estuarine systems. Numerous kinds of wetland exist in inland settings (e.g., bottom-land deciduous forests, coniferous dominated wetlands, fens, bogs, marshes, wet prairie, potholes), many of which have high site-level richness (Mitsch and Gosselink 2007), likely contributing to the greater mean richness across the NWCA inland wetland types. In contrast, the lower mean richness observed for estuarine wetlands may result, in part, from requirements for species to be adapted to saline conditions and tidal fluctuation of water levels (Keddy 2000).

Absolute cover of native species within growth-habit groups (Table 7) was used to describe natural vegetation structure, recognizing this natural structure could be impacted where native vegetation is strongly altered by human-mediated disturbance or replaced by nonnative plant species (Magee et al. 2008). Native vegetation structure varied most strongly by wetland type. For example, mean native forb cover was about 20 to $25 \%$ in inland wetland types, but only about $5 \%$ in estuarine wetland types. In contrast, mean native graminoid cover was greater in herbaceous (EH 75\%, PRLH 38\%) 


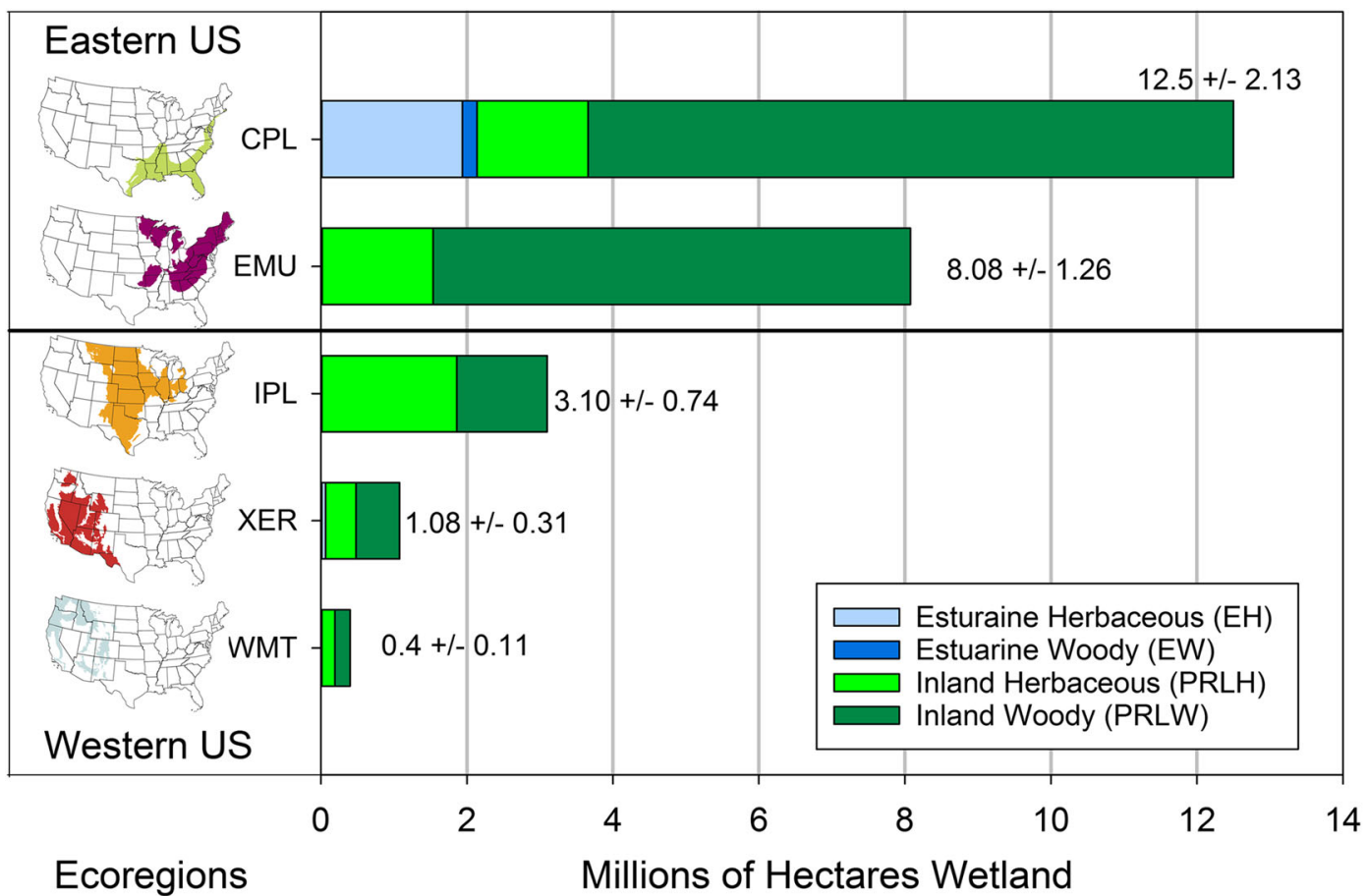

Fig. 2 Estimated wetland area in millions of hectares by wetland type within ecoregions for the National Wetland Condition Assessment sampled population. Ecoregions: CPL $=$ Coastal Plains, EMU = Eastern Mountains and Upper Midwest, IPL = Interior Plains, XER $=$ Xeric West, WMT $=$ Western Mountains and

Table 6 Estimated area in millions of hectares (ha) for wetland target population and the percent of target population represented by sampled (inference) population and subpopulations

\begin{tabular}{|c|c|c|}
\hline Region & $\begin{array}{l}\text { Estimated area target } \\
\text { population (millions ha) }\end{array}$ & $\begin{array}{l}\% \text { Target area } \\
\text { represented by } \\
\text { sampled population }\end{array}$ \\
\hline Conterminous US & $38.41 \pm 2.31$ & $65 \pm 3.9$ \\
\hline \multicolumn{3}{|l|}{ Ecoregion } \\
\hline CPL & $19.70 \pm 1.51$ & $63 \pm 5.7$ \\
\hline EMU & $10.00 \pm 1.16$ & $80 \pm 8.3$ \\
\hline IPL & $4.97 \pm 0.74$ & $62 \pm 7.7$ \\
\hline XER & $2.08 \pm 0.35$ & $52 \pm 9.5$ \\
\hline WMT & $1.65 \pm 0.56$ & $24 \pm 10.1$ \\
\hline \multicolumn{3}{|l|}{ Wetland type } \\
\hline $\mathrm{EH}$ & $2.27 \pm 0.42$ & $89 \pm 4.0$ \\
\hline EW & $0.40 \pm 0.12$ & $50 \pm 16.8$ \\
\hline PRLH & $10.41 \pm 0.92$ & $53 \pm 5.7$ \\
\hline PRLW & $25.34 \pm 2.01$ & $69 \pm 5.5$ \\
\hline
\end{tabular}

Margin of error estimates are two-sided 95\% confidence intervals. See Fig. 1 for ecoregion definition, Table 3 for wetland type descriptions, and Table 4 for sampled population areas
Valleys. See Table 3 for wetland type (EH, EW, PRLH, PRLW) definitions. See Supplement 2-Table A for tabular presentation of these results including $95 \%$ confidence intervals for wetland type area and number of sampled probability sites on which area estimates were based

than woody ( $E W \sim 28 \%$, PRLW $\sim 16 \%$ ) systems. Mean native shrub and tree cover were greatest in the woodydominated wetlands (EW, trees $\sim 52 \%$, shrubs $\sim 8 \%$; PRLW, trees $\sim 86 \%$, shrubs $\sim 18 \%$ ) as would be expected, and mean native tree cover was least in wetlands of the Xeric West $(\sim 2 \%)$ and Western Mountains and Valleys $(\sim 16 \%)$. Means for native vine cover were generally low, but vines were most prominent in inland woody wetland (PRLW $\sim 11 \%$ ) and in the Coastal Plains $(\sim 13 \%)$. The distribution of native species cover by growth-habit groups is likely to influence the trait requirements of nonnative species most adapted to invading different plant community types (Weihe and Neely 1997; Brewer 2011; Pyšek et al. 2012).

Not surprisingly, the largest differences in environmental conditions (Table 7) were observed across ecoregional subpopulations. Differences in the mean WI indicated wetlands in the Coastal Plains, the Eastern Mountains and Upper Midwest, and the Interior Plains had, on average, somewhat wetter overall hydrologic conditions than those in the Western Mountains and Valleys and the Xeric West. Among wetland types, the 


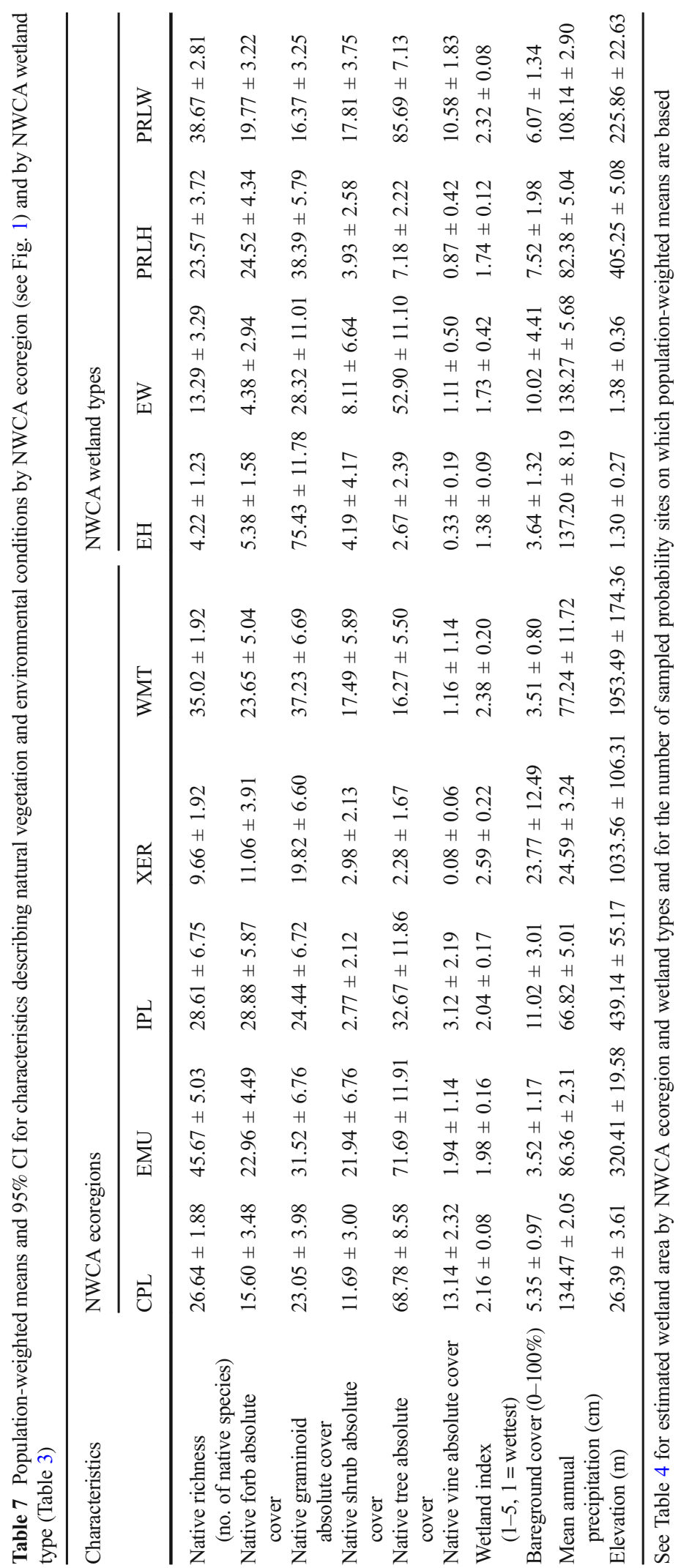


WI indicated the PRLW had on average somewhat drier conditions compared to other types. Mean annual precipitation was greatest in the Coastal Plains $(\sim 135 \mathrm{~cm})$, intermediate in the Eastern Mountains and Upper Midwest $(\sim 86 \mathrm{~cm})$ and the Western Mountains and Valleys $(\sim 77 \mathrm{~cm})$, somewhat less in the Interior Plains $(\sim$ $67 \mathrm{~cm})$, and least in the Xeric West $(\sim 25 \mathrm{~cm})$. WI and annual precipitation means may reflect general differences in available moisture that could facilitate or hinder some nonnative taxa over in situ native taxa, depending on the moisture regimes to which individual nonnative species are adapted (e.g., Magee and Kentula 2005; Dwire et al. 2006). Mean percent cover of exposed bareground was greatest in the Interior Plains $(\sim 11 \%)$ and Xeric West $(\sim 24 \%)$. Wetlands with more exposed bareground (i.e., lacking vegetation or vegetative litter), whether from natural processes or from humanmediated disturbance, could provide microsites for establishment of nonnative species (e.g., Quinn and Holt 2008). Mean elevation increased from east to west across the country, beginning in the Coastal Plains at $26 \mathrm{~m}$ and ranging to $1953 \mathrm{~m}$ in the Western Mountains and Valleys. Elevation represents gradients of temperature, moisture, and growing season length that can be expected to influence establishment or competitive ability of natives and nonnatives and select for nonnatives adapted to specific conditions (e.g., Averett et al. 2016).

Characterization of the complement of observed nonnative plant taxa

Across the 1138 sites sampled in the 2011 NWCA, 443 unique nonnative plant taxa were detected (see Supplement 1 -Ordered table of nonnative plants) and represented $12 \%$ of the total number (3640) of taxa observed (USEPA 2016d). Based on occurrences at the 2011 sampled sites, 80 of the observed nonnative taxa were found in three or more of the five NWCA ecoregions (see Supplement 1). More than half the 443 nonnative taxa were forbs (54\%) and $20 \%$ were graminoids, with trees (9\%), shrubs (7\%), and vines (10\%) encompassing smaller percentages of the observed nonnative flora. The number of nonnative taxa observed per site ranged from 0 to 29. Total nonnative cover (sum of absolute percent covers for all nonnative taxa occurring at a location) also varied markedly across individual sampled sites, ranging from 0 to $160 \%$. The array of nonnatives present, including the complement of specific taxa and growth habits (Supplement 1), suggests a species pool adapted to many ecological conditions, consequently representing diverse opportunities for invasion and interactions among nonnatives with varying impacts to native plant communities (e.g., Pyšek et al. 2012; Barney et al. 2013; Brewer and Bailey 2014; Kuebbing et al. 2014; Kuebbing et al. 2015; Rai 2015; Giorgis et al. 2016).

The 443 individual nonnative taxa encountered in the 2011 NWCA were found at between 1 and 166 of the sampled sites; 327 nonnative taxa were found at 5 or fewer sites, 50 occurred at 6-10 sites, and 51 occurred at 11-40 sites. Fifteen nonnative taxa were observed at more than 40 of the sampled sites: Phalaris arundinacea L. $(n=166)$, Poa pratensis L. ( $n=116)$, Taraxacum officinale F.h. Wigg. $(n=114)$, Phragmites australis (Cav.) Trin. Ex Steud. $(n=108)$, Rumex crispus L. $(n=96)$, Cirsium arvense (L.) Scop. $(n=77)$, Typha angustifolia L. $(n=67)$, Bromus inermis Leyss. $(n=50)$, Typha $\times$ glauca Godr. (Pro Sp.) $(n=49)$, Phleum pratense L. $(n=46)$, Solanum dulcamara L. $(n=46)$, Rosa multiflora Thunb. $(n=44)$, Elymus repens (L.) Gould $(n=43)$, Lonicera japonica Thunb. $(n=41)$, and Triadica sebifera (L.) Small $(n=41)$. The mean importance value (IV $=($ cover + frequency)/2) across sites of occurrence for these 15 most frequently observed nonnative taxa ranged from 25 to 47 . Nonnative taxa with higher mean importance at sites of occurrence may presage their increased invasiveness in wetlands going forward (e.g., Randall et al. 2008; Ehrenfeld 2010; Magee et al. 2010). In addition, $82 \%$ of the observed nonnative taxa are recognized as invasive, noxious, weedy, or invaders of natural areas (see Supplement 1). Although many of these aggressive taxa had low importance or were found only at a small number of NWCA sampled sites in 2011, the large number of nonnative taxa suggests a substantial invasion debt (sensu, Seabloom et al. 2006; Essl et al. 2011) for wetlands. At least some of these taxa are likely to expand in abundance and distribution and to have increasing impact over time; particularly, where (1) propagule pressures increase, (2) lag times in population growth or to reproductive maturity are overcome, (3) shifts in environmental conditions occur, (4) human-mediated disturbance increases (Seabloom et al. 2006; Rouget et al. 2016; Antunes and Schamp 2017; Dwire et al. 2017), or (5) with the advent of synergies among co-occurring nonnatives (Kuebbing et al. 2013; Kuebbing and Nuñez 2016). 
Estimates of wetland area by NNPI stressor-level

The NNPI is a categorical indicator of ecological stress from the assemblage of nonnative plants occurring at a given location. To characterize the extent of the 2011 NWCA sampled population wetland area with varying impacts from nonnative species, percent area and area in hectares were estimated within each of the four NNPI stressor-level (low, moderate, high, and very high) categories for the national scale and for the five ecoregional and four wetland type subpopulations. Although about $61 \%$ of the estimated wetland area in the sampled population across the conterminous US had low NNPI, nearly $20 \%$ of the wetland area exhibited high or very high NNPI (Fig. 3a). The national-scale distribution of wetland area within different NNPI stressor-levels was mirrored by the pattern observed in the Coastal Plains and in the Eastern Mountains and Upper Midwest (Fig. $3 a)$, which together encompass approximately $82 \%$ of the estimated wetland area in the sampled population (Fig. 2, Table 4). Even so, the percent area within specific NNPI stressor-levels varied markedly by ecoregion (Fig. 3a) and wetland type (Fig. 3b).

Based on percent area with high or very high NNPI, woody wetland types were less influenced by nonnatives than herbaceous wetland types, and estuarine herbaceous wetland appeared less affected than inland herbaceous wetland (Fig. 3b). About $68 \%$ of the inland woody (PRLW) wetland area had low NNPI, while about $11 \%$ of the area for this type fell in the high or very high categories. Estuarine woody (EW) wetland had the smallest percent area with high or very high NNPI; nearly all of its area was characterized as having low $(87 \%)$ or moderate (12\%) NNPI. In contrast, about $24 \%$ of the estuarine herbaceous (EH) wetland area fell into high or very high NNPI categories. Inland herbaceous (PRLH) wetland was the type most influenced by nonnative plants based on the extent estimates, with $43 \%$ of the area distributed between high and very high NNPI.

Nearly $90 \%$ of the wetland area in the eastern ecoregions (Coastal Plains and the Eastern Mountains and Upper Midwest) had low or moderate NNPI stressor-levels (Fig. 3a). In interpreting these results, it is important to note that the greatest area of PRLW wetland in the sampled population was found in these two eastern ecoregions, and all of the EW and most of the EH wetland occurred in the Coastal Plains (Fig. 2). These three wetland types each had large percent area with low or moderate NNPI (Fig. 3b) and, thus, contributed strongly to the prevalence of lower NNPI stressor-levels observed in the Coastal Plains and the Eastern Mountains and Upper Midwest (Fig. 3a). Although the NNPI stressor-level was low for these two regions in 2011, this could change over time in response to the complement of specific taxa that are present in the regional nonnative species pool (e.g., see Supplement 1 and the "Population means for absolute cover of nonnative growth-habit groups" section under "Exploratory analyses").

The percent area with high and very high NNPI was much greater in three western ecoregions (Interior Plains, Xeric West, and the Western Mountains and Valleys) than in the eastern ecoregions (Fig. 3a). Combined percentages of wetland area with high and very high NNPI were about $45 \%$ for the Interior Plains, $86 \%$ for the Xeric West, and 29\% for the Western Mountains and Valleys (Fig. 3a). Greater percent area in the higher stressor-levels for these ecoregions is likely related to greater percent area of PRLH wetlands compared to the Coastal Plains and the Eastern Mountains and Upper Midwest (Fig. 2), because the inland herbaceous type had the largest percent area with high and very high NNPI (Fig. 3b).

The sampled subpopulations for the Xeric West and the Western Mountains and Valleys represent about one half $(52 \%)$ and one fourth (24\%) of the target population area in these two regions, respectively (Table 6). Thus, it is possible that the 2011 sampled population may underor overrepresent the amount of area with specific NNPI stressor-levels across the target population of wetlands in these two ecoregions. Nevertheless, the relatively small estimated wetland area in the target population for the Xeric West and the Western Mountains and Valleys (see Table 6 and Olsen et al. (2019)) and the large percent of the sampled population area with high or very high NNPI in the Interior Plains, Xeric West, and the Western Mountains and Valleys indicate nonnative plant species pose strong threats to wetlands in these three ecoregions.

\section{Exploratory analyses}

The next four subsections include the results and discussion for four exploratory analyses that aid in the characterization of nonnative plants in wetlands at a variety of scales. Note, several individual species are highlighted in these subsections as examples illustrating particular points in the discussion, but they are not necessarily the most abundant or widespread nonnative taxa observed in the 2011 NWCA data. 
n Nonnative Plant Indicator (NNPI) Stressor-Level Extent Area (ha)
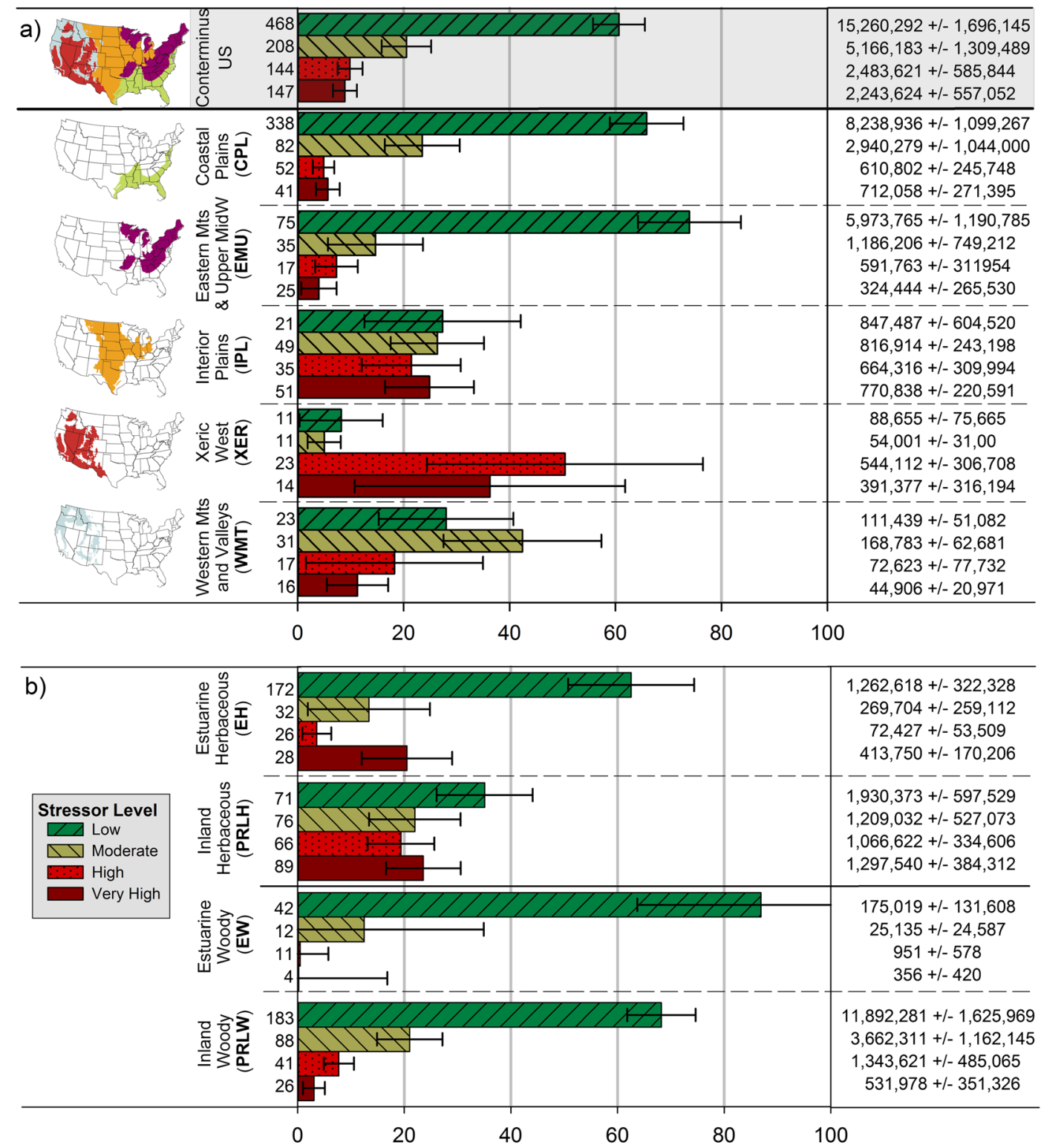

Percent Estimated Area

Fig. 3 Estimated wetland area in the National Wetland Condition Assessment sampled population by stressor-level category (low, moderate, high, and very high) for the nonnative plant indicator (NNPI). Subpopulation results are displayed in horizontal panels with bar charts reflecting percent area in each NNPI stressor-level; area in hectares (ha) is listed to the right of each bar. Results in graph a are for the conterminous US and ecoregional

\section{Population means for NNPI metrics}

In our first exploratory analysis, we evaluated populationweighted means $( \pm 95 \% \mathrm{CI})$ for each of the three NNPI subpopulations and in graph $\mathbf{b}$ for wetland type subpopulations. $n=$ number of sampled probability sites on which area estimates are based. Margins of error are two-sided 95\% confidence intervals. Note total wetland areas across ecoregions or across wetland types equal the total area in the NWCA sampled population at the national scale

metrics (Table 1) for ecoregional and wetland type subpopulations. Differences in means, based on nonoverlapping 95\% CIs, for the three NNPI metrics (Fig. 4, S2Table B) were observed among ecoregions and wetland 

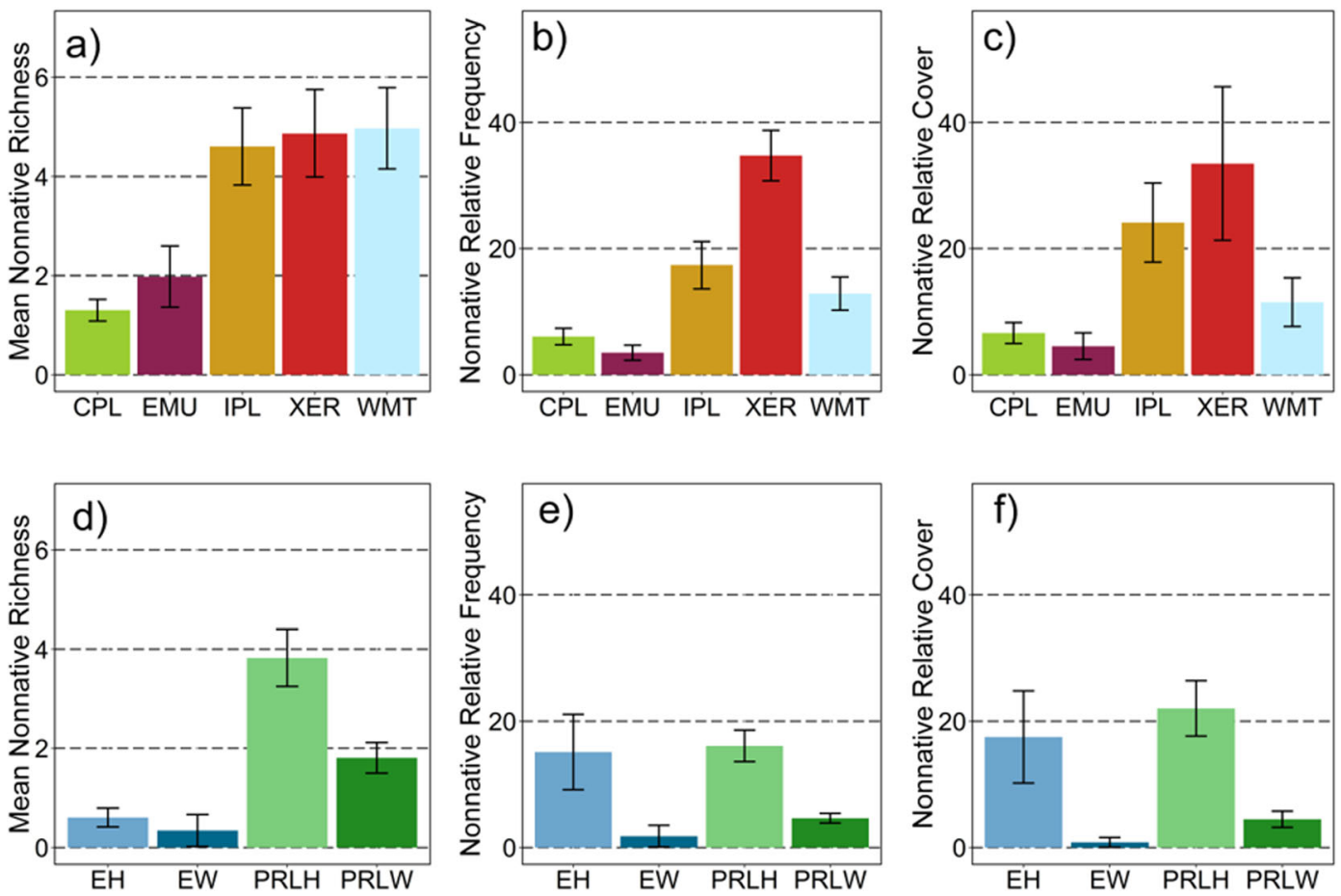

Fig. 4 Population-weighted mean and 95\% CI by ecoregion (a-c) and wetland type $(\mathbf{d}-\mathbf{e})$ for the three nonnative plant indicator (NNPI) component metrics (nonnative richness, nonnative relative frequency, and nonnative relative cover). Ecoregions: $\mathrm{CPL}=$ Coastal Plains, EMU = Eastern Mountains and Upper Midwest, $\mathrm{IPL}=$ Interior Plains, XER $=$ Xeric West, WMT $=$ Western Mountains and Valleys. Wetland type: $\mathrm{EH}=$ estuarine herbaceous, $\mathrm{EW}=$ estuarine woody, PRLH = inland herbaceous, PRLW = inland woody. See Table 3 for wetland type definitions. See Table 4 for estimated wetland area within NWCA ecoregion and wetland types and for the number of sampled probability sites on which population-weighted means are based. See Supplement 2-Table B for tabular presentation of these results types. As would be expected, these observations paralleled patterns in the area estimates by NNPI stressor-levels (Fig. 3), but the behavior of the individual metrics in the different subpopulations provides additional insights.

The western ecoregions (Interior Plains, Xeric West, and the Western Mountains and Valleys) all had mean nonnative richness (Fig. 4a) of approximately 5 species, compared to means of 1 to 2 nonnative species for the eastern ecoregions (Coastal Plains and the Eastern Mountains and Upper Midwest). Ecoregional patterns for nonnative relative frequency (Fig. $4 \mathrm{~b}$ ) and nonnative relative cover (Fig. 4c) were similar to one another, but both abundance metrics had lower values in the eastern than western ecoregions. Means for nonnative relative frequency and nonnative relative cover were similar in the Coastal Plains and the Eastern Mountains and Upper Midwest, ranging from about 4 to $7 \%$. In the Western Mountains and Valleys, means for nonnative relative frequency $(\sim$ $13 \%)$ and nonnative relative cover $(\sim 12 \%)$ exceeded those in the eastern ecoregions, but were substantially less than in the Interior Plains and Xeric West. Mean nonnative relative frequency and nonnative relative cover were greater in the Xeric West (frequency $\sim 35 \%$, cover $34 \%$ ) than in the Interior Plains (frequency $\sim 17 \%$, cover $\sim 24 \%$ ), although for cover, the CIs overlapped. Among wetland types, mean nonnative richness (Fig. 4d) was least in the estuarine systems $(\mathrm{EH}, \mathrm{EW})$ and was greater for inland herbaceous (PRLH 4) than inland woody (PRLW 2) systems. Mean relative nonnative frequency (Fig. 4e) was greater for herbaceous (EH 15\%, PRLH $16 \%$ ) than for woody wetlands (EW $\sim 1 \%$, PRLW 5\%). Likewise, mean relative nonnative cover (Fig. 4f) was much greater for herbaceous (EH 18\%, PRLH 22\%) than for woody wetland types (EW $\sim 1 \%$, PRLW $\sim 5 \%$ ).

Several hypotheses about ongoing threats from nonnative species to specific subpopulations are suggested by these results. First, all else being equal, greater colonization pressure related to higher numbers of nonnative species in a given location or across a region will 
increase the likelihood of nonnative species establishing in new areas (Lockwood et al. 2009), which, in turn, increases the probability that a harmful nonnative taxon (Alpert 2006), or synergistic interactions among nonnatives (Ricciardi et al. 2013), will be added to a plant community. Thus, greater mean richness of nonnative species in the western ecoregions vs. eastern ecoregions (Fig. 4a), or in inland herbaceous (PRLH) vs. other wetland types (Fig. 4d), suggests these subpopulations may be most vulnerable to the risk that one (or more) of the nonnatives present is or will become invasive or an ecosystem engineer. In contrast, lower mean nonnative richness in estuarine wetlands than in inland wetlands (Fig. 4d) likely relates, in part, to the pool of nonnative taxa able to establish or spread in estuarine wetlands being limited to those adapted to brackish or saline conditions. Nevertheless, salt-tolerant nonnative ecosystem engineers with wide ecologic amplitude pose ongoing threats to estuarine systems. For example, Phragmites australis (Cav.) Trin. ex Steud. occurred at 108 NWCA sampled sites (Supplement 1), 78 of which were estuarine sites. Although this species has a native component (Phragmites australis (Cav.) Trin. ex Steud. ssp. americanus Saltonst., P.M. Peterson \& Soreng), the aggressive nonnative subspecies (Phragmites australis (Cav.) Trin. ex Steud. ssp. australis) now dominates many inland and coastal marshes in the eastern US and has been increasingly observed in western locations (Chambers et al. 1999; Saltonstall 2002; Allen et al. 2017a). P. australis ssp. australis has the capacity to alter plant community composition and structure and ecosystem function (Silliman and Bertness 2004; Meyerson et al. 2010a; Uddin et al. 2017). In addition, the nonnative subspecies has been shown to hybridize with the native subspecies (Meyerson et al. 2010b; Saltonstall et al. 2014, 2016).

In the Xeric West and Interior Plains ecoregions (Fig. 4b) and for herbaceous wetland types (Fig. 4e), greater mean nonnative relative frequency may represent greater average numbers of nonnative foci per site for these subpopulations. More frequent occurrences of nonnatives can provide more locations from which nonnative taxa might disperse or expand across sites. In addition, higher values for relative frequency of nonnatives at a site could, in some circumstances, reflect increased potential for neighbor-to-neighbor competition between natives and nonnatives, possibly resulting in the reduced resiliency of the native plant community (e.g., Kuebbing and Nuñez 2016). High abundance or biomass of nonnative plants results in major changes in community composition and structure, which, in turn, often leads to alteration of ecosystem processes (e.g., Denslow and Hughes 2004; Hejda et al. 2009; Ehrenfeld 2010). Thus, the greater mean nonnative relative cover observed in 2011 (Fig. 4c) for wetlands of three western ecoregions compared to that observed in the two eastern ecoregions could reflect, on average, greater overall impact from nonnative plants in the western ecoregions. Given observed mean cover values, this is likely to be especially true for the Xeric West and Interior Plains regions. Further, although the mean nonnative relative cover in wetlands in the Western Mountains and Valleys was considerably less than for those in the Xeric West or Interior Plains (Fig. 4c), similar mean nonnative richness (Fig. 4a) suggests that wetlands in the Western Mountains and Valleys ecoregion may be at risk for increases in nonnative abundance. For example, some currently low cover nonnative species might transition from a lag phase (delayed or slow spread) to an expansion phase (rapid spread) of invasion (e.g., Simberloff 2011; Antunes and Schamp 2017).

\section{Population means for absolute cover of nonnative growth-habit groups}

Plant growth habit (e.g., graminoid, forb, vine, tree/shrub) is often related to other functional traits such as relative growth rate, height, or biomass (Lavorel et al. 2007), so the growth-habit type of nonnative plants can differentially influence their success in diverse ecosystems and environments (e.g., Herron et al. 2007; Tecco et al. 2010; Giorgis et al. 2016). Across the individual probability sites $(n=967)$ sampled in the 2011 NWCA, there was a wide range in absolute cover values for nonnative forbs $(0-98 \%)$, graminoids $(0-101 \%)$, shrub/trees (0-81\%), and vines (0-34\%). However, we wondered if the abundance of growth habits for nonnatives might vary at the scale of wetland populations. Thus, our second exploratory analysis was aimed at examining whether certain growth-habit types of nonnative taxa tended to be more abundant than others in different NWCA subpopulations.

We calculated population-weighted means $( \pm 95 \%$ CI), for nonnative absolute cover by four growth-habit groups for the five ecoregions and four wetland types (Fig. 5, S2-Table C). Across ecoregions (Fig. 5a), the greatest nonnative cover was observed for the forb (means ranging from $\sim 2$ to $13 \%$ ) and graminoid (means 


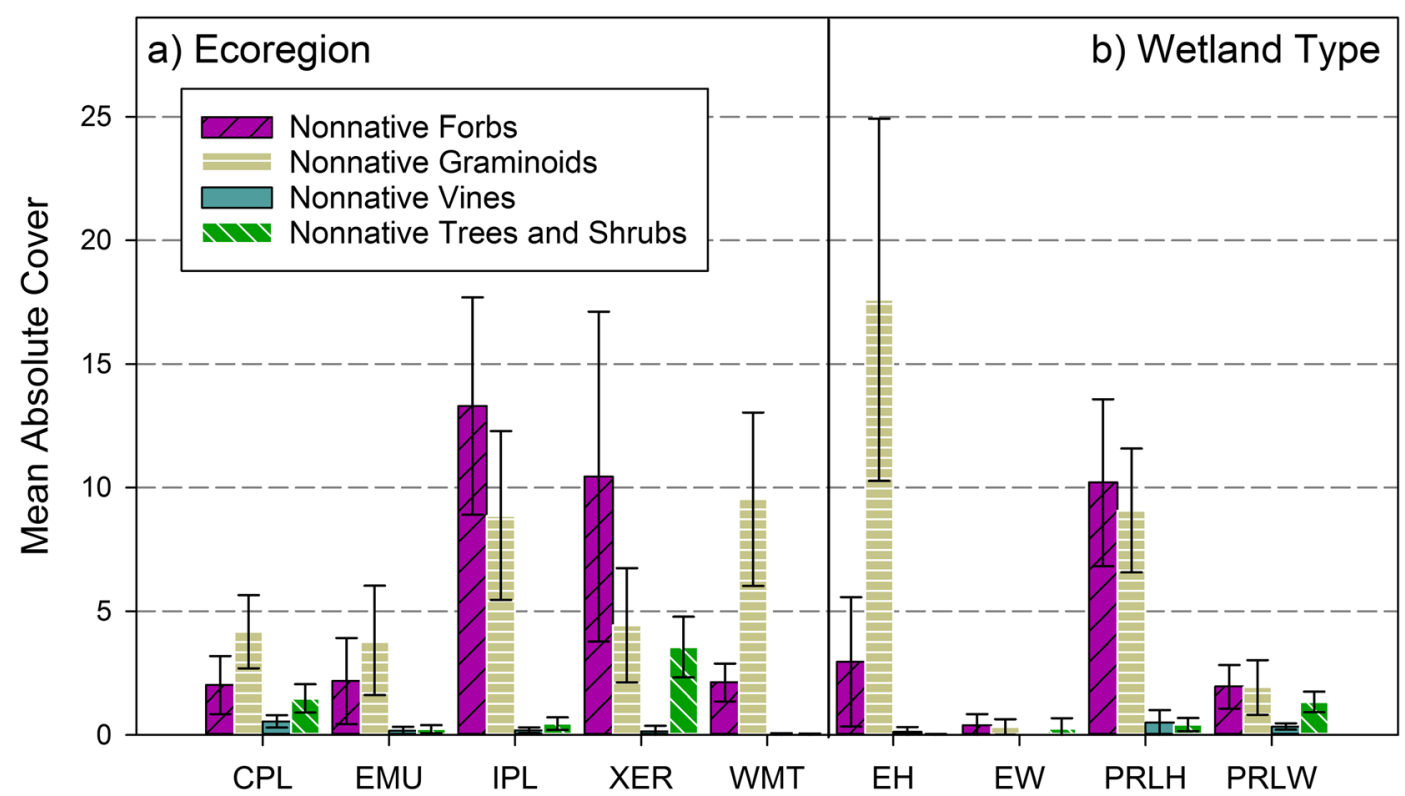

Fig. 5 Population-weighted mean and 95\% CI for the nonnative absolute percent cover in four growth-habit groups (forbs, graminoids, vines, and trees and shrubs) by ecoregion (a) and wetland type (b). Ecoregions: $\mathrm{CPL}=$ Coastal Plains, EMU = Eastern Mountains and Upper Midwest, IPL = Interior Plains, XER $=$ Xeric West, WMT $=$ Western Mountains and Valleys. Wetland type: $\mathrm{EH}=$ estuarine herbaceous, $\mathrm{EW}=$ estuarine woody,

ranging from $\sim 4$ to $10 \%$ ) groups. Nonnative absolute cover in the Western Mountains and Valleys was dominated by graminoids (mean $\sim 10 \%$ ). Although CIs were overlapping in the other four ecoregions, nonnative forbs tended to have greater mean cover than nonnative graminoids in the Interior Plains and Xeric West, whereas the reverse was true in the Coastal Plains and in the Eastern Mountains and Upper Midwest. Forbs and graminoids also made up most of the nonnative cover in the inland and estuarine herbaceous wetland types (Fig. 5b), with mean nonnative cover of forbs and graminoids about equal $(\sim 10 \%)$ in the PRLH, and graminoids the most abundant nonnative growth-habit group $(\sim 18 \%)$ in the EH. In contrast, the nonnative vine and tree/shrub groups had low mean cover $(<1$ to about $3.5 \%$ ) across all subpopulations (Fig. 5a, b). Mean nonnative vine cover was greatest in the Coastal Plains (Fig. 5a) but still represented only a small amount of the nonnative plant cover for wetlands in this region. The greatest values for mean nonnative tree/shrub cover were observed in the Coastal Plains $(\sim 1.5 \%)$ and Xeric West $(\sim 4 \%)$ (Fig. 5a) and in inland woody wetlands (PRLW 1.4\%) (Fig. 5b). Based on these results, the population-scale means for absolute cover indicate that
PRLH = inland herbaceous, PRLW = inland woody. See Table 3 for wetland type definitions. See Table 4 for the number of sampled probability sites and the estimated wetland area within the NWCA ecoregion and wetland types on which populationweighted means are based. See Supplement 2-Table C for tabular presentation of these results

in 2011, on average, graminoid and forb nonnative taxa had more extensively invaded wetlands across the five ecoregions of the sampled population than taxa in the vine or tree/shrub groups, especially for herbaceous wetland types.

This pattern is perhaps not unexpected because, globally, numerous nonnative forb and grass (Poaceae) species are known to be highly successful invaders and many have been associated with ecological impact (Pyšek et al. 2012, 2017; Linder et al. 2018). Forb species that are tall and capable of forming populations with cover greater than the dominant native species, for example, have been shown to negatively impact plant communities (e.g., Hejda et al. 2009). Nonnative grasses are particularly successful because of their capacity to colonize, persist, dominate vegetation, and transform environments with impacts on ecosystem processes, resource availability, and local disturbance regimes (Martina and von Ende 2013; Gebauer et al. 2016; Linder et al. 2018). Canopy cover from trees and shrubs likely limits the establishment of shade-intolerant nonnative forbs and graminoids in woody wetlands. However, shade-tolerant nonnative taxa of all growth forms are often competitive in forested settings, and many 
have detrimental long-term impacts (Martin et al. 2009). Consequently, even though the mean absolute cover for nonnative forbs and graminoids in woody wetlands in the NWCA population was low in 2011, going forward, shade-tolerant nonnative forbs and graminoids may pose greater threat as they come into equilibrium with their potential introduced ranges. For instance, in the 2011 NWCA, the shade-tolerant annual grass, Microstegium vimineum (Trin.) A. Camus, was found at 20 sampled sites with a mean importance of 35 at sites of occurrence (Supplement 1). M. vimineum forms dense monocultures and alters nitrogen cycling (DeMeester and Richter 2010) and soil microbial communities (Kourtev et al. 2002; North and Torzilli 2017), and its greatest negative community-level effects occur in shady forested settings (Brewer 2011; Brewer and Bailey 2014).

Although mean absolute cover of nonnative vines (including lianas and species transitional between vines and shrubs) was low across the NWCA sampled population (Fig. 5), it was greatest in the Coastal Plains and in inland herbaceous wetlands (PRLH), and wetlands in these subpopulations may be at increased risk for expansions of nonnative vine cover in the future. A diverse set of 24 nonnative vine species was observed in the Coastal Plain sites sampled in 2011; many of these vine taxa are strong invaders (see Supplement 1 , * next to PLANTS Symbol). Invasive vines can usurp space, overtop other vegetation, alter availability of light and nutrients, change habitat to facilitate other invasive taxa, and alter fire regimes (e.g., Lonicera japonica Thunb. (GISD 2018) and Lygodium japonicum (Thunb.) Sw. (CABI 2018b)). In 2011, Lonicera japonica occurred at 41 NWCA sampled sites (35 in the Coastal Plains) and Lygodium japonicum was found at 10 sites (all in the Coastal Plains) (Supplement 1). In addition to the 24 vine taxa primarily observed in the Coastal Plains in 2011, other vine species were found across sampled sites in one or multiple ecoregions, and many of these were also recognized as invasive (Supplement 1). For example, Solanum dulcamara L. was found in 46 sampled sites across all five ecoregions and Rubus armeniacus Focke was observed only at 4 sites in the Western Mountains and Valleys; however, both are highly invasive and readily overtop native vegetation (Waggy 2009; CABI 2018c).

Mean absolute cover values for the nonnative tree/ shrub group tended to be low; however, inland woody systems had greater mean nonnative cover for this growth-habit group than other wetland types (Fig. 5b). The Coastal Plains and the Eastern Mountains and Upper Midwest ecoregions had the greatest prevalence and percent of woody wetland area (Fig. 2), and across all 2011 NWCA sites sampled for these two ecoregions, 43 nonnative taxa in the tree/shrub growth-habit group were observed, with 9 of these taxa detected in both regions, and all 43 are recognized as invasive, noxious, weedy, and/or known invaders of natural areas (Supplement 1). Thus, it will be important to watch for changes over time in the amount of woody wetland area with high or very high NNPI. Due to tall stature, canopy structure, and longevity, nonnative trees and shrubs are often ecosystem engineers that can alter overall plant community structure and composition, nutrient inputs, soil biota, and light regimes (Reinhart et al. 2006). As a result, nonnative trees and shrubs may have potential for increased expansion in cover and impact over time in both herbaceous and woody systems, as lag times related to height growth and reproductive age are overcome (e.g., Martin et al. 2009). Nonnative tree or shrub species with wide ecologic amplitude could have potential impacts on a variety of wetland types. For instance, the introduced tree Triadica sebifera (L.) Small thrives in fresh to saltwater and in sunny to shady conditions, displaces native plant species, forms monotypic stands, and alters nutrient cycles (GISD 2015), and it was observed in the Coastal Plains ecoregion at 41 NWCA sampled sites encompassing all four NWCA wetland types. Among ecoregions, the Xeric West had the highest population mean for absolute nonnative tree/ shrub cover (Fig. 5a), and this result likely reflects occurrences of Tamarix chinensis Lour. and Elaeagnus angustifolia L., which were the two most commonly observed species in this growth habit for sampled sites in this ecoregion (Supplement 1). Both species are aggressive invaders and ecosystem engineers of riparian wetlands, altering successional trajectories as well as soil and hydrologic conditions (Lindgren et al. 2010; CABI 2018a).

\section{Characterization of human-mediated disturbance in the sampled population}

Although not all nonnative plant species require disturbance to invade natural plant communities, humanmediated disturbances (either at the site level or in the surrounding landscape) are often linked to increased levels of invasion by nonnative plant species (e.g., 
Alpert et al. 2000; Silliman and Bertness 2004; Ehrenfeld 2008; Ringold et al. 2008; Brewer and Bailey 2014; Herlihy et al. 2019b). So, in our third exploratory analysis, we examined three descriptors of human-mediated disturbance (Fig. 6, S2-Table D) to see if, at the scale of the 2011 NWCA ecoregional and wetland type subpopulations, disturbance patterns paralleled NNPI extent results (Fig. 3).

We found that the population-weighted means for (1) the index describing overall site-level disturbance, and (2) for percent agriculture and percent developed land in the 1000-m surrounding each site, did vary by ecoregion (Fig. 6a-c) and wetland type (Fig. 6d-f). Mean values for the site-level disturbance index were greater in the Xeric West $(\sim 11)$ and the Western Mountains and Valleys ( $\sim 9)$ compared to the other three ecoregions (Coastal Plains, Eastern Mountains and Upper Midwest, Interior Plains) where the mean ranged from about 3 to 5 (Fig. 6a). Among wetland types, site-level disturbance was greatest in the inland systems and was higher for the herbaceous (PRLH 6) than the woody (PRLW 4) type (Fig. $6 \mathrm{~d})$. Mean percent agriculture within the $1000-\mathrm{m}$ radius surrounding each probability site (Fig. 6b) was greatest in the Interior Plains $(\sim 43 \%)$, substantial in the Coastal Plains $(\sim 20 \%)$ and Xeric West $(\sim 16 \%)$, somewhat less for the Eastern Mountains and Upper Midwest $(\sim 10 \%)$, and lowest in the Western Mountains and Valleys $(\sim 5 \%)$. Results also show that mean percent surrounding agriculture was small in the subpopulation of estuarine wetlands, but much higher for the inland wetland subpopulations (PRLH $\sim 32 \%$, PRLW 17), particularly for the herbaceous type (Fig. 6e). Values for mean percent developed land in the $1000-\mathrm{m}$ surrounding probability sites were relatively low ( $<10 \%$ with CIs tending to overlap) both for ecoregions (Fig. 6c) and wetland types (Fig. 6f), but was least for estuarine herbaceous wetland $(\mathrm{EH} \sim$ $2 \%$ ), and greatest for the estuarine woody (EW $10 \%$ ) and inland herbaceous (PRLH $\sim 8 \%$ ) types.
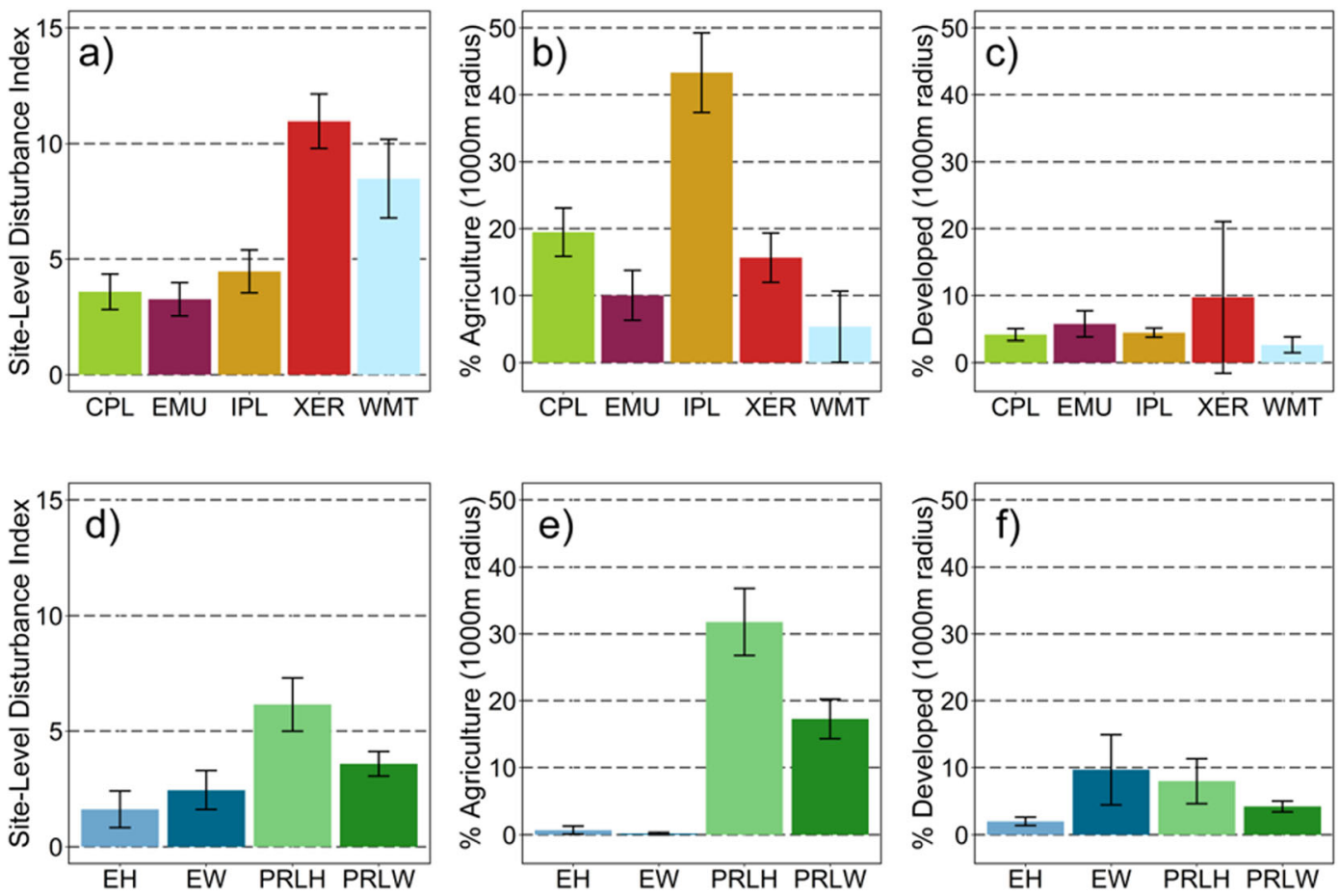

Fig. 6 Population-weighted means and 95\% CI (error bars) by ecoregion $(\mathbf{a}-\mathbf{c})$ and wetland type $(\mathbf{d}-\mathbf{e})$ for the three metrics of human-mediated disturbance (site-level disturbance index, and percent agriculture and percent developed land use in the 1000$\mathrm{m}$ radius around each sampled site). Ecoregions: $\mathrm{CPL}=\mathrm{Coastal}$ Plains, EMU = Eastern Mountains and Upper Midwest, IPL = Interior Plains, XER $=$ Xeric West, WMT $=$ Western Mountains and Valleys. Wetland type: $\mathrm{EH}=$ estuarine herbaceous, EW = estuarine woody, PRLH = inland herbaceous, PRLW = inland woody. See Table 3 for wetland type definitions. See Table 4 for estimated wetland area within the NWCA ecoregion and wetland types and for the number of sampled probability sites on which population-weighted means are based. See Supplement 2 - Table D for tabular presentation of these results 
Qualitative comparison of the disturbance results (Fig. 6) with percent area by NNPI stressor-level category for each wetland subpopulation (Fig. 3) suggests that a large percent area with high or very high NNPI is associated, at least in part, with high levels of humanmediated disturbance. This is most evident for site-level disturbance and percent surrounding agriculture, where the three ecoregions (Interior Plains, Xeric West, and Western Mountains and Valleys) with high means for these two disturbance metrics also have the greatest percent area with high and very high NNPI status (Fig. $3)$. In the Interior Plains, the high mean percent surrounding agriculture for wetlands may result in (1) propagule and colonization pressure from nonnative taxa associated with agricultural settings, (2) changes in wetland nutrient dynamics or influx of contaminants through fertilizer or pesticide run-off, and (3) changes in hydrology due to farming practices (e.g., tiling, irrigation run-off, or direct water extraction), all processes that can enhance the success of nonnative taxa. Overall site-level disturbance observed in 2011 was greatest for wetlands in the Xeric West and the Western Mountains and Valleys (Fig. 6a). Key elements of the site-level disturbance for these two regions are reflected in related NWCA work for the combined wetland area of the Xeric West and the Western Mountains and Valleys subpopulations, where approximately 61,70 , and $75 \%$ of this area were estimated to have high stressor-levels for vegetation removal (e.g., grazing, mowing), soil hardening (e.g., animal trampling, trails, impervious surfaces), and ditching, respectively (USEPA 2016c). These three physical stressors are likely to alter ecosystem properties (e.g., hydrology, vegetation structure, resource availability) and facilitate spread and establishment (e.g., via grazing animals, trail or road corridors, water transport of propagules) of nonnatives. Among the wetland type subpopulations, inland herbaceous wetland (PRL), in addition to having the greatest percent area in high or very high NNPI status (Fig. 3), also exhibited the greatest means for both site-level disturbance and percent agriculture (Fig. 6d, e).

\section{Ecological relationships with site-level NNPI status}

In our final exploratory analysis, we shifted from the population-scale to a site-scale focus to evaluate which ecological attributes might be most strongly associated with site-level NNPI status. Results discussed in previous sections suggested interactions between NNPI stressor-levels and ecoregion, wetland type, natural vegetation attributes, environmental characteristics, and disturbance descriptors. Consequently, we used RF analysis to explore how this set of ecological attributes and their potential interactions might collectively relate to the NNPI status at individual NWCA sampled sites. All sampled sites $(n=1138)$ and 15 predictor variables (ten native vegetation and environmental characteristics, Table 7; three disturbance descriptors, Fig. 6; NWCA ecoregion, Fig. 1; and NWCA wetland type, Table 3, Fig. 1) were included in the RF analysis.

The RF analysis performed well, correctly classifying the two NNPI combined stressor-level categories (low-moderate and high-very high) $84 \%$ of the time for all sites, $86 \%$ of the time for low-moderate sites, and $77 \%$ of the time for high-very high sites (Fig. 7), based on the collective set of predictor variables. The RF variable importance plot (Fig. 7) shows the relative importance of each predictor in distinguishing sites likely to have high-very high vs. low-moderate NNPI stressor-levels. Partial dependence plots for all predictor variables are provided in Supplement 3 (S3), Figs. A-O, and indicate the specific relationship of each individual predictor with the probability of the occurrence of highvery high NNPI status. Note, all partial dependence plots exhibited nonlinear relationships. Considering the order of variable importance (Fig. 7) and partial dependence plots for the individual predictor variables used in the RF (S3) together highlights some key associations.

Wetland type (S3-Fig. H) and ecoregion (S3-Fig. K) were, respectively, the eighth and 11th most important predictors of NNPI (Fig. 7). This ranking is interesting because the 2011 area estimates for NNPI stressor-levels (Fig. 3) and the population-weighted means for the natural vegetation and environmental attributes (Table 7) and disturbance metrics (Fig. 6) varied with ecoregional and wetland type subpopulations. Nevertheless, although wetland type and ecoregion are important in predicting high-very high NNPI at the site level, other metrics may more specifically reflect site-level conditions associated with a given NNPI status.

Metrics related to moisture conditions were strong predictors based on variable importance in the RF analysis. The wetland index (WI) had the greatest variable importance (Fig. 7), with the likelihood of a site having high-very high NNPI status increasing with larger WI values (S3-Fig. A). Higher WI reflects lower abundance of obligate (OBL) or facultative wetland (FACW) indicator species and typically drier conditions (Wentworth et al. 
Fig. 7 Variable importance plot for random forests classification of NNPI in two combined stressor-level categories $(\mathrm{LM}=$ low and moderate, $\mathrm{HVH}=$ high and very high). Predictor variables are listed on the left. Higher values for mean decrease in accuracy indicate greater importance of a predictor variable to the classification. Percent of sites correctly classified (PCC) by the model are listed in the text box for All, LM, and HVH sites

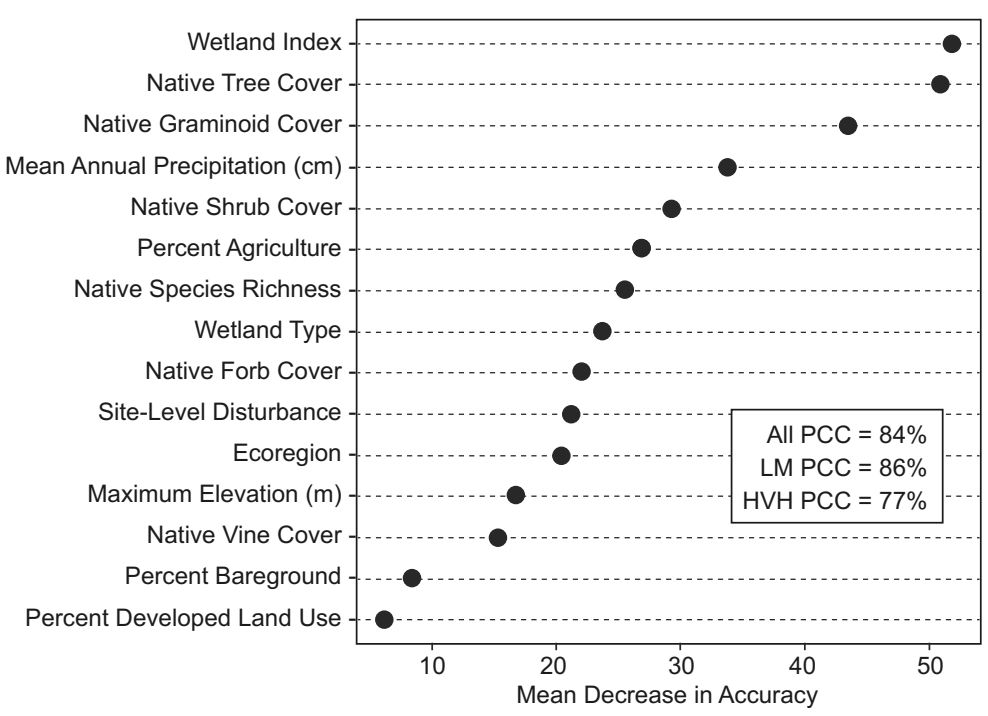

1988). Among the 443 nonnative taxa observed across the 1138 sampled sites (Supplement 1), only 105 taxa had OBL or FACW indicator status. More than $75 \%$ of the observed nonnative taxa were facultative (FAC, no. of taxa $=88$ ), facultative upland (FACU, no. of taxa $=117$ ), or upland (UPL, no. of taxa $=116)$ indicators, suggesting that many of these nonnative taxa might be more prevalent at drier wetland sites. In addition, mean annual precipitation was the fourth most important predictor of NNPI status (Fig. 7), with probability of high-very high NNPI status greatest for sites where annual precipitation was less than $50 \mathrm{~cm}$ (S3-Fig. D).

Elevation and percent bareground, the two other environmental metrics evaluated, were among the weaker predictors in the suite of ecological attributes included in the RF, with variable importance at the 12th and 14th positions, respectively (Fig. 7). However, elevation greater than about $2500 \mathrm{~m}$ was associated with lower probability of having high-very high NNPI than lower elevations (S3-Fig. L). The 23 sampled sites with elevations greater that $2500 \mathrm{~m}$ were distributed in mountains across Arizona, Colorado, Nevada, New Mexico, and Utah. Higher elevations often are related to more extreme environments and to greater distance from nonnative propagule sources which could limit nonnative establishment; however, the growth form of invading nonnatives can differentially influence invasibility at higher elevations (Giorgis et al. 2016). Sites with less than about $25 \%$ bareground had much lower probability of having high-very high NNPI than sites with more bareground (S3-Fig. N), suggesting that in some situations greater amounts of available bareground may represent unexploited habitat for nonnatives (e.g., Quinn and Holt 2008).

Native vegetation structure is an ecosystem property that can influence the influx of nonnative plants (see discussion in the "Characterization of the 2011 NWCA sampled population" and "Population means for absolute cover of nonnative growth-habit groups" sections). This was reflected in absolute cover of native trees and native graminoids having the second and third highest variable importance in the RF analysis (Fig. 7). The probability of high-very high NNPI was greatest when there was no tree cover, decreased steadily as native tree cover increased from 0 to about $60 \%$, then dropped precipitously until native tree cover exceeded $100 \%$, where the probability of high-very high was lowest (S3-Fig. B). Greater cover of native trees can limit establishment and abundance of many shade-intolerant nonnatives. However, shade-tolerant nonnatives, including invasive shrubs, trees, graminoids, and vines, did occur in forest-dominated locations (Supplement 1), and, over time, these taxa might be expected to expand both their site-level cover and regional occurrence. Considering native graminoid cover alone (S3-Fig. C), the likelihood of having high-very high NNPI was least where native graminoids were abundant (e.g., 75 to $200 \%$ absolute cover), but increased more or less linearly as graminoid cover dropped from 75 to $0 \%$. Greater native graminoid cover can contribute to exclusion of some nonnatives through competition and physical barriers where sod or thatch are formed. 
Native absolute shrub and forb cover were the fifth and ninth most important predictors (Fig. 7), with the probability of having high-very high NNPI steadily increasing as native cover declined, beginning from about $50 \%$ cover for native shrubs (S3-Fig. E) and at about $100 \%$ for forbs (S3-Fig. I). Native shrubs may limit shade-intolerant nonnatives. Native vine cover was 13th in variable importance (Fig. 7), and the partial dependence plot did not indicate a clear response of NNPI to native vine cover alone (S3-Fig. M), possibly because native vine absolute cover tended to be low except in the Coastal Plains ecoregion (Table 7). In our RF model, native species richness was the seventh most important predictor (Fig. 7), with its partial dependence plot (S3-Fig. G) showing a complex pattern in relation to the probability of occurrence of high-very high NNPI stressor-level, which was greatest when native richness was low (e.g., about 15 or fewer species), least when native richness ranged from about 20 to 70 species, and intermediate when native richness was greater.

Human-mediated disturbance was related to increased probability of high-very high NNPI status. The disturbance metrics included in the RF analysis varied in importance. Percent agriculture in the $1000 \mathrm{~m}$ surrounding a site was the sixth most important predictor in the RF (Fig. 7), but among the three disturbance metrics, it had the strongest relationship to increasing likelihood of high-very high NNPI. The sitelevel disturbance index and the percent developed land in the $1000 \mathrm{~m}$ surrounding a site were the tenth and 15 th most important predictor variables in the RF model, respectively (Fig. 7). Nevertheless, the partial dependence plots show marked increase in probability of occurrence of high-very high NNPI with increasing values for all three of the disturbance metrics (percent agriculture, S3-Fig. F; site-level disturbance, S3-Fig. J; percent developed land, S3-Fig. O), suggesting that increases in any of these disturbance measures are likely to be associated with greater stress from nonnatives.

This exploratory RF analysis effectively classified site-level NNPI status; so, the relative importance of predicator variables in this exploratory model is likely to be a useful starting point in informing monitoring or management efforts. For example, for a given ecological setting, NNPI status and site-level values for specific predictor variables might suggest possible pathways of risk for increasing impact from nonnative plants or management actions that could potentially aid in reducing nonnative success.

\section{Summary and next steps}

As part of the 2011 NWCA, this study is unique in scope. It characterizes the status of nonnative plants in wetlands for a sampled population representing approximately 25 million ha of wetland and allows results to be viewed at a variety of scales, e.g., nationally, or for major ecoregional and wetland type subpopulations. To provide an ecological context for our work, we described the sampled population in terms of (1) estimated area by wetland type within ecoregions (Fig. 2) and (2) population-weighted means for a variety of ecological attributes describing natural vegetation structure and environmental characteristics by ecoregion and wetland type (Table 7). We used several approaches to evaluate nonnative plants in wetlands. First, we characterized the complement of nonnative plant species observed during the 2011 NWCA. The 443 nonnative plant taxa observed across NWCA sampled sites (Supplement 1) reflected a species pool adapted to many ecological conditions, thus providing diverse opportunities for continued invasion and potential impact to wetlands and other ecosystems.

Next, we considered potential impact from nonnative species, as indicated by the NNPI, by examining the extent of the 2011 NWCA sampled population (percent area and hectares of wetland) that fell into the four NNPI stressor-level categories (Fig. 3). Results at the scale of the conterminous US indicated nearly $20 \%$ of wetland area in the sampled population had high to very high NNPI. However, ecological stress from nonnatives varied markedly by ecoregion and wetland type. The extent patterns for NNPI stressor-levels observed at the national scale were driven by the large wetland area in the eastern ecoregions (the Coastal Plains and the Eastern Mountains and Upper Midwest) where nearly $90 \%$ of the wetland area was estimated to have low to moderate NNPI, which likely relates to the prevalence of woody wetland types in these two regions. Woody wetland types had greater percent area in lower NNPI stressor-level categories than herbaceous wetland types across the NWCA sampled population. In contrast, although the overall wetland area was much smaller in the western ecoregions (Interior Plains, Xeric West, and the Western Mountains and Valleys) than in eastern ecoregions, a much greater percent of the wetland area in the western regions had high to very high NNPI (ranging from about 27 to $87 \%$ ). This pattern is related, at least in part, to the greater proportion of the wetland area in inland herbaceous types in the western ecoregions. 
We also conducted a series of exploratory analyses that provide ecological information that aids in interpreting patterns described by the NNPI extent results. Three population-scale analyses examined ecoregional and wetland type population means for (1) the three NNPI metrics (nonnative richness, relative frequency, and relative cover, Fig. 4), (2) absolute cover for four growth-habit groups of nonnative plants (Fig. 5), and (3) three metrics describing human-mediated disturbance (Fig. 6). Results from these three analyses highlight some potential avenues of impact from nonnative plants, which vary ecoregionally and by wetland type and could suggest associations with the 2011 observed patterns for NNPI or suggest risks for future incursions of nonnatives. In addition, qualitative comparisons of the NNPI results with results of populationscale exploratory analyses suggested interactions between NNPI stressor-levels and ecoregion, wetland type, natural vegetation attributes, environmental characteristics, and human-mediated disturbance. Consequently, we examined ecological relationships with site-level NNPI status using a RF analysis (Fig. 7, Supplement 3) and NNPI as the response variable with predictor variables including ecoregion, wetland type, and a variety of characteristics describing natural vegetation structure, environment, and human-mediated disturbance. This exploratory RF correctly classified sitelevel NNPI for a combined high-very high class $77 \%$ of the time; thus, the relative importance of variables in this exploratory model may be useful in informing future research or monitoring efforts.

Examination of the NNPI patterns and the ecological relationships indicated by the exploratory analyses can help inform national or regional management and conservation priorities for wetlands, or suggest research questions that would support management needs. Moving forward, as additional data are collected in future NWCA assessments, changes over time in the NNPI stressor-levels can be used to assess whether impact from nonnative plants in wetlands is increasing. The second iteration of the NWCA was implemented in the field during the summer of 2016, with an expanded survey design to allow more complete representation of the wetland area across the conterminous US, particularly for the western part of the country (Olsen et al. 2019). As the 2016 data are considered, it will be possible to evaluate changes in wetland area within NNPI stressor-levels between 2011 and 2016. Finally, the results for the NNPI from the 2011 and 2016 assessments are likely to suggest a variety of specific questions that might be addressed in future research using NWCA data (USEPA 2016e). For example, modeling approaches (e.g., Seabloom et al. 2006; Thuiller et al. 2006; Schweiger et al. 2016; Hill et al. 2017) might be used to elucidate ecological correlates or mechanisms associated with stress from nonnative plants, or to predict and map locations with low or high stress from nonnatives at varying geographic scales.

Acknowledgements The 2011 NWCA was planned, funded, and organized by the USEPA. The NWCA data used in this paper resulted from collaborative efforts of many dedicated field crews, laboratory staff, data management and quality control personnel, and scientists from USEPA, states, tribes, federal agencies, universities, and other organizations. More information about these data can be obtained from nars-hq@epa.gov. We thank Mary E. Kentula (USEPA-National Health and Environmental Effects Laboratory (NHEERL), Western Ecology Division (WED)) for her support and insightful discussions and suggestions. Jim Markwiese (USEPA-NHEERL-WED) provided quality assurance review. Thoughtful comments from Billy Schweiger (Rocky Mountain Network, National Park Service) and two anonymous reviewers enhanced the paper. We thank Thomas Kincaid (USEPA-NHEERLWED) for his assistance with calculation of some of the population estimates of wetland area discussed in this paper. This manuscript has been subjected to review by USEPA-NHEERL-WED and approved for publication. Views expressed in this paper are those of the authors and do not necessarily reflect the views or policies of the USEPA. Mention of trade names or commercial products does not constitute endorsement or recommendation for use.

Funding information The USEPA funded the work presented in this paper. Portions of work conducted on this project by ATH were supported by grant no. RD-83425201 from the National Center for Environmental Research STAR Program of the US EPA, an intergovernmental personnel agreement with the USEPA Office of Water, and by a National Research Council (NRC) Senior Research Associateship award at USEPA-NHEERL-WED.

Open Access This article is distributed under the terms of the Creative Commons Attribution 4.0 International License (http:// creativecommons.org/licenses/by/4.0/), which permits unrestricted use, distribution, and reproduction in any medium, provided you give appropriate credit to the original author(s) and the source, provide a link to the Creative Commons license, and indicate if changes were made.

\section{References}

Aguiar, F. C., Ferreira, M. T., Albuquerque, A., \& Moreira, I. (2007). Alien and endemic flora at reference and nonreference sites in Mediterranean-type streams in Portugal. Aquatic Conservation: Marine and Freshwater Ecosystems, 17(4), 335-347. https://doi.org/10.1002/aqc.1776. 
Allen, G. A., McCormick, L. J., Jantzen, J. R., Marr, K. L., \& Brown, B. N. (2017a). Distributional and morphological differences between native and introduced common reed (Phragmites australis, Poaceae) in Western Canada. Wetlands, 37(5), 819-827. https://doi.org/10.1007/s13157017-0914-4.

Allen, W. J., Meyerson, L. A., Cummings, D., Anderson, J., Bhattarai, G. P., \& Cronin, J. T. (2017b). Biogeography of a plant invasion: drivers of latitudinal variation in enemy release. Global Ecology and Biogeography, 26(4), 435-446. https://doi.org/10.1111/geb.12550.

Alpert, P. (2006). The advantages and disadvantages of being introduced. Biological Invasions, 8(7), 1523-1534. https://doi.org/10.1007/s10530-005-5844-z.

Alpert, P., Bone, E., \& Holzapfel, C. (2000). Invasiveness, invasibility and the role of environmental stress in the spread of non-native plants. Perspectives in Plant Ecology, Evolution and Systematics, 3(1), 52-66.

Antunes, P. M., \& Schamp, B. (2017). Constructing standard invasion curves from herbarium data - toward increased predictability of plant invasions. Invasive Plant Science and Management, 10(4), 293-303. https://doi.org/10.1017 /inp.2017.38.

Averett, J. P., McCune, B., Parks, C. G., Naylor, B. J., DelCurto, T., \& Mata-Gonzàlez, R. (2016). Non-native plant invasion along elevation and canopy closure gradients in a middle rocky mountain ecosystem. PLoS One, 11(1), 24. https://doi.org/10.1371/journal.pone.0147826.

Baiser, B., Lockwood, J., La Puma, D., \& Aronson, M. (2008). A perfect storm: two ecosystem engineers interact to degrade deciduous forests of New Jersey. Biological Invasions, 10(6), 785-795.

Barney, J. N., Tekiela, D. R., Dollete, E. S. J., \& Tomasek, B. J. (2013). What is the "real" impact of invasive plant species? Frontiers in Ecology and the Environment, 11(6), 322-329. https://doi.org/10.1890/120120.

Beauvais, M.-P., Pellerin, S., \& Lavoie, C. (2016). Beta diversity declines while native plant species richness triples over 35 years in a suburban protected area. Biological Conservation, 195, 73-81. https://doi.org/10.1016/j.biocon.2015.12.040.

Belnap, J., \& Phillips, S. L. (2001). Soil biota in a ungrazed grassland: response to annual grass (Bromus tectorum) invasion. Ecological Applications, 11(5), 1261-1275.

Bennett, J. R., Vellend, M., Lilley, P. L., Cornwell, W. K., \& Arcese, P. (2013). Abundance, rarity and invasion debt among exotic species in a patchy ecosystem. Biological Invasions, 15(3), 707-716. https://doi.org/10.1007/s10530012-0320-z.

Blackburn, T. M., Essl, F., Evans, T., Hulme, P. E., Jeschke, J. M., Kühn, I., Kumschick, S., Marková, Z., Mrugała, A., Nentwig, W., Pergl, J., Pyšek, P., Rabitsch, W., Ricciardi, A., Richardson, D. M., Sendek, A., Vilà, M., Wilson, J. R. U., Winter, M., Genovesi, P., \& Bacher, S. (2014). A unified classification of alien species based on the magnitude of their environmental impacts. PLoS Biology, 12(5), e1001850. https://doi.org/10.1371/journal.pbio. 1001850.

Bowen, J. L., Kearns, P. J., Byrnes, J. E. K., Wigginton, S., Allen, W. J., Greenwood, M., Tran, K., Yu, J., Cronin, J. T., \& Meyerson, L. A. (2017). Lineage overwhelms environmental conditions in determining rhizosphere bacterial community structure in a cosmopolitan invasive plant. Nature
Communications, 8(1), 433. https://doi.org/10.1038/s41467017-00626-0.

Bradley, B. A., Houghton, R. A., Mustard, J. F., \& Hamburg, S. P. (2006). Invasive grass reduces aboveground carbon stocks in shrublands of the western US. Global Change Biology, 12, 1815-1822.

Brewer, J. S. (2011). Per capita community-level effects of an invasive grass, Microstegium vimineum, on vegetation in mesic forests in northern Mississippi (USA). Biological Invasions, 13(3), 701-715. https://doi.org/10.1007/s10530010-9861-1.

Brewer, J. S., \& Bailey, W. C. (2014). Competitive effects of nonnative plants are lowest in native plant communities that are most vulnerable to invasion. Plant Ecology, 215(8), 821832. https://doi.org/10.1007/s11258-014-0334-y.

Brodersen, C., Lavergne, S., \& Molofsky, J. (2008). Genetic variation in photosynthetic characteristics among invasive and native populations of reed canarygrass (Phalaris arundinacea). Biological Invasions, 10(8), 1317-1325.

Brooks, M. L., D’Antonio, C. M., Richardson, D. M., Grace, J. B., Keeley, J. E., DiTomaso, J. M., Hobbs, R. J., Pellant, M., \& Pyke, D. (2004). Effects of invasive alien plants on fire regimes. BioScience, 54(7), 677-688.

CABI (2018a). Elaeagnus angustifolia [original text by Nick Pasiecznik, 2008]. In: Invasive species compendium. Wallingford, UK: CAB International. www.cabi.org/isc. Accessed 25 July 2008.

CABI (2018b). Lygodium japonicum [original text by Keith A. Bradley, South Carolina, USA, 2015]. In: Invasive species compendium. Wallingford, UK: CAB International. www. cabi.org/isc. Accessed 17 July 2018.

CABI (2018c). Rubus armeniacus [original text by Madeleine Florin, the Netherlands, 2015]. In: Invasive species compendium. Wallingford, UK: CAB International. www.cabi. org/isc. Accessed 17 July 2018.

Carlton, J. T. (1996). Biological invasions and cryptogenic species. Ecology, 77, 1653-1655.

Chambers, R. M., Meyerson, L. A., \& Saltonstall, K. (1999). Expansion of Phragmites australis into tidal wetlands of North America. Aquatic Botany, 64, 261-273.

Cutler, D. R., Edwards, T. C., Beard, K. H., Cutler, A., Hess, K. T., Gibson, J., \& Lawler, J. J. (2007). Random forests for classification in ecology. Ecology, 88(11), 2783-2792. https://doi.org/10.1890/07-0539.1.

D'Antonio, C., \& Flory, S. L. (2017). Long-term dynamics and impacts of plant invasions. Journal of Ecology, 105(6), 1459-1461. https://doi.org/10.1111/1365-2745.12879.

Dahl, T. E. (2011). Status and trends of wetlands in the conterminous United States 2004 to 2009 (p. 108). Washington, D.C.: U.S. Department of the Interior; Fish and Wildlife Service.

Dahl, T. E., \& Bergeson, M. T. (2009). Technical procedures for conducting status and trends of the nation's wetlands (p. 74). Washington, D.C.: U.S. Fish and Wildlife Services, Division of Habitat and Resource Conservation.

Daly, C., Halbleib, M., Smith, J. I., Gibson, W. P., Doggett, M. K., Taylor, G. H., Curtis, J., \& PP, M. (2008). Physiographically sensitive mapping of climatological temperature and precipitation across the conterminous United States. International Journal of Climatology, 28(2031-2064), 2031-2064. 
De'ath, G., \& Fabricius, K. E. (2000). Classification and regression trees: a powerful yet simple technique for ecological data analysis. Ecology, 81(11), 3178-3192.

DeMeester, J. E., \& Richter, D. d. (2010). Differences in wetland nitrogen cycling between the invasive grass Microstegium vimineum and a diverse plant community. Ecological Applications, 20(3), 609-619. https://doi.org/10.1890/090283.1.

Denslow, J. S., \& Hughes, R. F. (2004). Exotic plants as ecosystem dominants. Weed Technology, 18, 1283-1287.

Diaz-Ramos, S., Stevens, D. L., Jr., \& Olsen, A. R. (1996). EMAP statistical methods manual. EPA/620/r-96/002. Corvallis, Oregon: U.S. Environmental Protection Agency, Office of Research and Development, NHEERL-Western Ecology Division.

Dukes, J. S., \& Mooney, H. A. (1999). Does global change increase the success of biological invaders? Trends in Ecology and Evolution, 14(4), 135-139.

Dukes, J. S., \& Mooney, H. A. (2004). Disruption of ecosystem processes in western North America by invasive species. Revista Chilena de Historia Natural, 77(3), 411-437.

Dwire, K. A., \& Kauffman, J. B. (2003). Fire and riparian ecosystems in landscapes of western USA. Forest Ecology and Management, 178, 61-74.

Dwire, K. A., Kauffman, J. B., \& Baham, J. E. (2006). Plant species distribution in relation to water-table depth and soil redox potential in montane riparian meadows. Wetlands, 26(1), 131-146.

Dwire, K. A., Mellmann-Brown, S., \& Gurrieri, J. T. (2017). Potential effects of climate change on riparian areas, wetlands, and groundwater-dependent ecosystems in the Blue Mountains, Oregon, USA. Climate Services, 10, 44-52. https://doi.org/10.1016/j.cliser.2017.10.002.

Ehrenfeld, J. G. (2003). Effects of exotic plant invasions on soil nutrient cycling processes. Ecosystems, 6(6), 503-523.

Ehrenfeld, J. G. (2008). Exotic invasive species in urban wetlands: environmental correlates and implications for wetland management. Journal of Applied Ecology, 45(4), 1160-1169. https://doi.org/10.1111/j.1365-2664.2008.01476.x.

Ehrenfeld, J. G. (2010). Ecosystem consequences of biological invasions. Annual Review of Ecology, Evolution, and Systematics, 41, 59-80.

Ehrenfeld, J. G., Kourtev, P., \& Huang, W. (2001). Changes in soil functions following invasions of exotic understory forests. Ecological Applications, 11(5), 1287-1300.

Essl, F., Dullinger, S., Rabitsch, W., Hulme, P. E., Hülber, K., Jarošík, V., Kleinbauer, I., Krausmann, F., Kühn, I., Nentwig, W., Vilà, M., Genovesi, P., Gherardi, F., Desprez-Loustau, M.-L., Roques, A., \& Pyšek, P. (2011). Socioeconomic legacy yields an invasion debt. Proceedings of the National Academy of Sciences, 108(1), 203-207. https://doi. org/10.1073/pnas.1011728108.

Farnsworth, E. J., \& Meyerson, L. A. (2003). Comparative ecophysiology of four wetland plant species along a continuum of invasiveness. Wetlands, 23(4), 750-762.

Fox, E. W., Hill, R. A., Leibowitz, S. G., Olsen, A. R., Thornbrugh, D. J., \& Weber, M. H. (2017). Assessing the accuracy and stability of variable selection methods for random forest modeling in ecology. Environmental Monitoring and Assessment, 189(7), 316. https://doi.org/10.1007 /s10661-017-6025-0.
Fry, J., Xian, G., Jin, S., Dewitz, J., Homer, C., Yang, L., Barnes, C., Herold, N., \& Wickham, J. (2011). Completion of the 2006 National Land Cover Database for the conterminous United States, https://www.mrlc.gov/nlcd2006.php, Accessed June 2013. Photogrammetric Engineering and Remote Sensing, 77(9), 858-864.

Galatowitsch, S. M., Anderson, N. O., \& Ascher, P. D. (1999). Invasiveness in wetland plants in temperate North America. Wetlands, 19, 733-755.

Gebauer, A. D., Brown, R., Schwab, S., Nezat, C., \& McNeely, C. (2016). Effects of an invasive grass (Phalaris Arundinacea) on water availability in semi-arid riparian zones. Wetlands, 36(1), 59-72. https://doi.org/10.1007/s13157-015-0716-5.

Gilbert, B., \& Levine, J. M. (2013). Plant invasions and extinction debts. Proceedings of the National Academy of Science, 110(5), 1744-1749. https://doi.org/10.1073 /pnas. 1212375110 .

Giorgis, M. A., Cingolani, A. M., Tecco, P. A., Cabido, M., Poca, M., \& von Wehrden, H. (2016). Testing alien plant distribution and habitat invasibility in mountain ecosystems: growth form matters. Biological Invasions, 18(7), 2017-2028. https://doi.org/10.1007/s10530-016-1148-8.

GISD ( 2015). Global invasive species database. Species profile Triadica sebifera. Available from: http:/www.iucngisd. org/gisd/species.php?sc=712. Accessed 9 July 2018.

GISD (2018). Global invasive species database. Species profile: Lonicera japonica. Downloaded from http://www.iucngisd. org/gisd/speciesname/Lonicera+japonica. Accessed 18 July 2018.

Hejda, M., Pyšek, P., \& Jarošík, V. (2009). Impact of invasive plants on the species richness, diversity and composition of invaded communities. Journal of Ecology, 97(3), 393-403. https://doi.org/10.1111/j.1365-2745.2009.01480.x.

Herlihy, A. T., Paulsen, S. P., Van Sickle, J., Stoddard, J. L., Hawkins, C. P., \& Yuan, L. (2008). Striving for consistency in a national assessment: the challenges of applying a reference condition approach at a continental scale. Journal of the North American Benthological Society, 27(4), 860-877. https://doi.org/10.1899/08-081.1.

Herlihy, A. T., Kentula, M. E., Magee, T. K., Lomnicky, G. A., Nahlik, A. M., Serenbetz, G. (2019a). Striving for consistency in the National Wetland Condition Assessment: developing a reference condition approach for assessing wetlands at a continental scale. Environmental Monitoring and Assessment. https://doi.org/10.1007/s10661-019-7325-3.

Herlihy, A. T., Sifneos, J. C., Lomnicky, G. A., Nahlik, A. M., Kentula, M. E., Magee, T. K., Weber, M. H., \& Trebitz, A. S. (2019b). The response of wetland quality indicators to human disturbance across the United States. Environmental Monitoring and Assessment. https://doi.org/10.1007 /s10661-019-7323-5.

Herron, P. M., Martine, C. T., Latimer, A. M., \& Leicht-Young, S. (2007). Invasive plants and their ecological strategies: prediction and explanation of woody plant invasion in New England. Diversity and Distributions, 13(5), 633-644.

Hill, R. A., Fox, E. W., Leibowitz, S. G., Olsen, A. R., Thornbrugh, D. J., \& Weber, M. H. (2017). Predictive mapping of the biotic condition of conterminous-USA rivers and streams. Ecological Applications, 27(8), 2397-2415. https://doi.org/10.1002/eap.1617. 
Hooper, D. U., Chapin, F. S., III, Ewel, J. J., Hector, A., Inchausti, P., Lavorel, S., Lawton, J. H., Lodge, D. M., Loreau, M., Naeem, S., Schmid, B., Setälä, H., Symstad, A. J., Vandermeer, J., \& Wardle, D. A. (2005). Effects of biodiversity on ecosystem functioning: a consensus of current knowledge. Ecological Monographs, 75(1), 3-35.

Jakubowski, A. R., Jackson, R. D., \& Casler, M. D. (2014). The history of reed canarygrass in North America: persistence of natives among invading Eurasian populations. Crop Science, 54 (1), 210-219. https://doi.org/10.2135 /cropsci2013.05.0342.

Kaufmann, P. R., Levine, P., Robison, E. G., Seeliger, C., \& Peck, D. V. (1999). Quantifying physical habitat in wadable streams, EPA/620/R-99/003. Washington, D.C: U.S. Environmental Protection Agency.

Keddy, P. A. (2000). Wetland ecology: principles and conservation (Cambridge studies in ecology). New York, New York: Cambridge University Press.

Kentula, M. E., \& Paulsen, S. G. (2019). The 2011 National Wetland Condition Assessment: overview and an invitation. Environmental Monitoring and Assessment. https://doi. org/10.1007/s10661-019-7316-4.

Kincaid, T. M., \& Olsen, A. R., Jr. (2015). spsurvey: spatial survey design and analysis. R package version 3.1 (https://cran.rproject.org/package=spsurvey).

Kourtev, P. S., Ehrenfeld, J. G., \& Häggblom, M. (2002). Exotic plant species alter the microbial community structure and function in the soil. Ecology, 83(11), 3152-3166. https:// doi.org/10.1890/0012-9658(2002)083[3152: EPSATM]2.0.CO;2.

Kuebbing, S. E., \& Nuñez, M. A. (2016). Invasive non-native plants have a greater effect on neighbouring natives than other non-natives. Nature Plants, 2, 16134. https://doi. org/10.1038/nplants.2016.134 http://www.nature. com/articles/nplants2016134\#supplementary-information.

Kuebbing, S. E., Nuñez, M. A., \& Simberloff, D. (2013). Current mismatch between research and conservation efforts: the need to study co-occurring invasive plant species. Biological Conservation, 160, 121-129. https://doi. org/10.1016/j.biocon.2013.01.009.

Kuebbing, S. E., Souza, L., \& Sanders, N. J. (2014). Effects of cooccurring non-native invasive plant species on old-field succession. Forest Ecology and Management, 324, 196-204. https://doi.org/10.1016/j.foreco.2013.10.031.

Kuebbing, S. E., Classen, A. T., Sanders, N. J., \& Simberloff, D. (2015). Above- and below-ground effects of plant diversity depend on species origin: an experimental test with multiple invaders. New Phytologist, 208(3), 727-735. https://doi. org/10.1111/nph.13488.

Lavorel, S., Diaz, S., Cornelissen, J. H. C., Garnier, E., Harrison, S. P., McIntyre, S., Pausas, J., Pérez-Harguindeguy, N., Roumet, C., \& Urcelay, C. (2007). Plant functional types: are we getting any closer to the Holy Grail? In J. G. Canadell, D. E. Pataki, \& L. F. Pitelka (Eds.), Terrestrial ecosystems in a changing world. Berlin: Springer.

Lesica, P. (1997). Spread of Phalaris arundinacea adversely impacts the endangered plant Howellia aquatilis. Great Basin Naturalist, 57, 366-368.

Liaw, A., \& Wiener, M. (2002). Classification and regression by randomForest. $R$ News, 2(3), 18-22.
Liaw, A., \& Wiener, M. (2015). 'randomForest': Breiman and Cutler's random forests for classification and regression. $\mathrm{R}$ package version 4.6-12. (https://CRAN.R-project. org/package=randomForest).

Linder, H. P., Lehmann, C. E. R., Archibald, S., Osborne, C. P., \& Richardson, D. M. (2018). Global grass (Poaceae) success underpinned by traits facilitating colonization, persistence and habitat transformation. Biological Reviews, 93(2), 1125-1144. https://doi.org/10.1111/brv.12388.

Lindgren, C., Pearce, C., \& Allison, K. (2010). The biolgy of invasive alien plants in Canada. 11 Tamarix ramosissima Ledeb., T. chinensis Lour. and hybrids. Canadian Journal of Plant Science, 90, 111-124.

Liu, Y., Oduor, A. M. O., Zhang, Z., Manea, A., Tooth, I. M., Leishman, M. R., Xu, X., \& van Kleunen, M. (2017). Do invasive alien plants benefit more from global environmental change than native plants? Global Change Biology, 23(8), 3363-3370. https://doi.org/10.1111/gcb.13579.

Lockwood, J. L., Cassey, P., \& Blackburn, T. M. (2009). The more you introduce the more you get: the role of colonization pressure and propagule pressure in invasion ecology. Diversity and Distributions, 15(5), 904-910.

Lomnicky, G.A., Herlihy, A. T., Kaufmann, P. R. (2019). Quantifying the extent of human disturbance activities and anthropogenic stressors in wetlands across the conterminous United States - results from the National Wetland Condition Assessment. Environmental Monitoring and Assessment. https://doi.org/10.1007/s10661-019-7314-6.

Lozon, J. D., \& MacIsaac, H. J. (1997). Biological invasions: are they dependent on disturbance? Environmental Reviews, 5(2), 131-144.

Mack, J. J., \& Kentula, M. E. (2010). Metric similarity in vegetation-based wetland assessment methods. EPA/600/R10/140. Washington, D.C.: U.S. Environmental Protection Agency, Office of Research and Development.

Mack, R. N., Simberloff, D., Lonsdale, M. S., Evans, H., Clout, M., \& Bazzaz, F. A. (2000). Biotic invasions: causes, epidemiology, global, consequences, and control. Ecological Applications, 10(3), 698-710.

Magee, T. K., \& Kentula, M. E. (2005). Response of wetland plant species to hydrologic conditions. Wetlands Ecology and Management, 13, 163-181. https://doi.org/10.1007/s11273004-6258-x.

Magee, T. K., Ernst, T. L., Kentula, M. E., \& Dwire, K. A. (1999). Floristic comparison of freshwater wetlands in an urbanizing environment. Wetlands, 19(3), 517-534.

Magee, T. K., Ringold, P. L., \& Bollman, M. A. (2008). Alien species importance in native vegetation along wadeable streams, John Day River basin, Oregon, USA. Plant Ecology, 195, 287-307. https://doi.org/10.1007/s11258007-9330-9.

Magee, T. K., Ringold, P. L., Bollman, M. A., \& Ernst, T. L. (2010). Index of alien impact (IAI): a method for evaluating alien plant species in native ecosystems. Environmental Management, 45, 759-778. https://doi.org/10.1007/s00267010-9426-1.

Magee, T. K., Blocksom, K. A., \& Fennessy, M. S. (2019). A national-scale vegetation multimetric index (VMMI) as an indicator of wetland condition across the conterminous United States. Environmental Monitoring and Assessment. https://doi.org/10.1007/s10661-019-7324-4. 
Martin, P. H., Canham, C. D., \& Marks, P. L. (2009). Why forests appear resistant to exotic plant invasions: intentional introductions, stand dynamics, and the role of shade tolerance. Frontiers in Ecology and the Environment, 7(3), 142-149. https://doi.org/10.1890/070096.

Martina, J. P., \& von Ende, C. N. (2013). Increased spatial dominance in high nitrogen, saturated soil due to clonal architecture plasticity of the invasive wetland plant, Phalaris arundinacea. Plant Ecology, 214(12), 1443-1453. https://doi.org/10.1007/s11258-013-0265-Z.

McCauley, D. J., Arnold, W. J., Saxton, J. B., \& Turner, C. J. (2019). Applying adaptive management and lessons learned from national assessments to address logistical challenges in the National Wetlands Condition Assessment. Environmental Monitoring and Assessment. https://doi.org/10.1007/s10661019-7320-8.

McKay, L., Bondelid, T., Dewald, T., Johnston, J., Moore, R., \& Reah, A. (2012). NHDPlus version 2: user guide. ftp://ftp. horizonsystems. com/NHDPlus/NHDPlus V2 1 /Documentation/NHDPlus-V2_User_Guide.pdf. Date accessed: September 2013.

McKinney, M. L. (2004). Measuring floristic homogenization by non-native plants in North America. Global Ecology and Biogeography, 13(47-53), 47-53.

Meyerson, L. A., \& Mooney, H. A. (2007). Invasive alien species in an era of globalization. Frontiers in Ecology and the Environment, 5(4), 199-208.

Meyerson, L. A., Lambert, A. M., \& Saltonstall, K. (2010a). A tale of three lineages: expansion of common reed (Phragmites australis) in the U.S. southwest and Gulf Coast. Invasive Plant Science and Management, 3, 515-520.

Meyerson, L. A., Viola, D. V., \& Brown, R. N. (2010b). Hybridization of invasive Phragmites australis with a native subspecies in North America. Biological Invasions, 12(1), 103-111. https://doi.org/10.1007/s10530-009-9434-3.

Mitsch, W. J., \& Gosselink, J. G. (2007). Wetlands (4th ed.). Hoboken, N.J: Wiley.

Nahlik, A. M., Blocksom, K. A., Herlihy, A. T., Kentula, M. E., Magee T.K., and Paulsen, S.G. (2019). Use of national-scale data to examine human-mediated additions of heavy metals to wetland soils of the United States. Environmental Monitoring and Assessment. https://doi.org/10.1007 /s10661-019-7315-5.

North, B. A., \& Torzilli, A. P. (2017). Characterization of the root and soil mycobiome associated with invasive Microstegium vimineum in the presence and absence of a native plant community. Botany, 95(5), 513-520. https://doi.org/10.1139 /cjb-2016-0235.

Olsen, A. R., Kincaid, T. M., Kentula, M. E., \& Weber, M. H. (2019). Survey design to assess condition of wetlands in the United States. Environmental Monitoring and Assessment. https://doi.org/10.1007/s10661-019-7322-6.

PRISM Climate Group (2013). Oregon State University. http://prism.oregonstate.edu. Accessed September 2013.

Pyšek, P., Jarošík, V., Hulme, P. E., Pergl, J., Hejda, M., Schaffner, U., \& Vilà, M. (2012). A global assessment of invasive plant impacts on resident species, communities and ecosystems: the interaction of impact measures, invading species' traits and environment. Global Change Biology, 18(5), 17251737. https://doi.org/10.1111/j.1365-2486.2011.02636.x.
Pyšek, P., Pergl, J., Essl, F., Lenzner, B., Dawson, W., Kreft, H., Weigelt, P., Winter, M., Kartesz, J., Nishino, M., Antonova, L. A., Barcelona, J. F., Cabezas, F. J., Cárdenas, D., Cárdenas-Toro, J., Castańo, N., Chacón, E., Chatelain, C., Dullinger, S., Ebel, A. L., Figueiredo, E., Fuentes, N., Genovesi, P., Groom, Q. J., Henderson, L., Inderjit, Kupriyanov, A., Masciadri, S., Maurel, N., Meerm, J., Morozova, O., Moser, D., Nickrent, D., Now, P. M., Pagad, S., Patzelt, A., Pelser, P. B., Seebens, H., Shu, W.-S., Thomas, J., Velayos, M., Weber, E., Wieringa, J. J., Baptiste, M. P., \& vanKleunen, M. (2017). Naturalized alien flora of the world: species diversity, taxonomic and phylogenetic patterns, geographic distribution and global hotspots of plant invasion. Preslia, 89, 203-274. https://doi.org/10.23855 /preslia.2017.203.

Quinn, L., \& Holt, J. (2008). Ecological correlates of invasion by Arundo donax in three southern California riparian habitats. Biological Invasions, 10(5), 591-601.

R_Core_Team. (2015). R: a language and environment for statistical computing. Vienna: R Foundationfor Statistical Computing. http://www.R-project.org/.

R Core Team. (2017). R: a language and environment for statistical computing. Vienna: R Foundationfor Statistical Computing. http://www.R-project.org/.

Rai, P. K. (2015). Paradigm of plant invasion: multifaceted review on sustainable management. Environmental Monitoring and Assessment, 187(12), 759. https://doi.org/10.1007/s10661015-4934-3.

Randall, J. M. (1996). Weed control for the preservation of biological diversity. Weed Technology, 10, 370-383.

Randall, J. M., Morse, L. E., Benton, N., Hiebert, R., Lu, S., \& Killeffer, T. (2008). The invasive species assessment protocol: a tool for creating regional and national lists of invasive nonnative plants that negatively impact biodiversity. Invasive Plant Science and Management, 1, 36-49.

Reinhart, K. O., Gurnee, J., Tirado, R., \& Callaway, R. M. (2006). Invasion through quantitative effects: intense shade drives native decline and invasive success. Ecological Applications, 16(5), 1821-1831.

Ricciardi, A., Hoopes, M. F., Marchetti, M., \& Lockwood, J. L. (2013). Progress toward understanding the ecological impacts of nonnative species. Ecological Monographs, 83(3), 263-282.

Richardson, D. M., \& Pyšek, P. (2006). Plant invasions: merging the concepts of species invasiveness and community invasibility. Progress in Physical Geography, 30(3), 409431. https://doi.org/10.1191/030913306pp490pr.

Ringold, P. L., Magee, T. K., \& Peck, D. V. (2008). Twelve invasive plant taxa in US western riparian ecosystems. Journal of the North American Benthological Society, 27(4), 949-966. https://doi.org/10.1899/07-154.1.

Rooney, T. P., Wiegmann, S. M., Rogers, D. A., \& Waller, D. M. (2004). Biotic impoverishment and homogenization in unfragmented forest understory communities. Conservation Biology, 18(3), 787-798.

Rouget, M., Robertson, M. P., Wilson, J. R. U., Hui, C., Essl, F., Renteria, J. L., \& Richardson, D. M. (2016). Invasion debtquantifying future biological invasions. Diversity and Distributions, 22(4), 445-456. https://doi.org/10.1111 /ddi.12408. 
Rowantree, K. (1991). An assessment of the potential impact of alien invasive vegetation on the geomorphology of river channels in South Africa. South African Journal of Aquatic Science, 17, 28-43.

Sala, A., Smith, S. D., \& Devitt, D. A. (1996). Water use by Tamarix ramosissima and associated phreatophytes. Ecological Applications, 6, 888-898.

Sala, A., Smith, S. D., \& Devitt, D. A. (1996). Water use by Tamarix ramosissima and associated phreatophytes. Ecological Applications, 6, 888-898.

Saltonstall, K. (2002). Cryptic invasion by a non-native genotype of the common reed, Phragmites australis, into North America. Proceedings of the National Academy of Sciences, 99(4), 2445-2449. https://doi.org/10.1073/pnas.032477999.

Saltonstall, K., Castillo, H. E., \& Blossey, B. (2014). Confirmed field hybridization of native and introduced Phragmites australis (Poaceae) in North America. American Journal of Botany, 101(1), 211-215. https://doi.org/10.3732 /ajb.1300298.

Saltonstall, K., Lambert, A. M., \& Rice, N. (2016). What happens in Vegas, better stay in Vegas: Phragmites australis hybrids in the Las Vegas Wash. Biological Invasions, 18(9), 24632474. https://doi.org/10.1007/s10530-016-1167-5.

Schweiger, E. W., Grace, J. B., Cooper, D., Bobowski, B., \& Britten, M. (2016). Using structural equation modeling to link human activities to wetland ecological integrity. Ecosphere, 7(11), e01548. https://doi.org/10.1002 /ecs01542.01548.

Seabloom, E., Williams, J., Slayback, D., Stoms, D., Viers, J., \& Dobson, A. (2006). Human impacts, plant invasion, and imperiled plant species in California. Ecological Applications, 16(4), 1338-1350.

Sifneos, J. C., Herlihy, A. T., Jacobs, A. D., \& Kentula, M. E. (2010). Calibration of the Delaware Rapid Assessment Protocol to a comprehensive measure of wetland condition. Wetlands, 30(6), 1011-1022. https://doi.org/10.1007 /s13157-010-0093-z.

Silliman, B. R., \& Bertness, M. D. (2004). Shoreline development drives invasion of Phragmites australis and the loss of plant diversity on New England salt marshes. Conservation Biology, 18(5), 1424-1434. https://doi.org/10.1111/j.15231739.2004.00112.x.

Simberloff, D. (2006). Invasional meltdown 6 years later: important phenomenon, unfortunate metaphor, or both? Ecology Letters, 9(8), 912-919. https://doi.org/10.1111/j.14610248.2006.00939.x.

Simberloff, D. (2011). How common are invasion-induced ecosystem impacts? Biological Invasions, 13(5), 1255-1268. https://doi.org/10.1007/s10530-011-9956-3.

Simberloff, D., Souza, L., Nunez, M. A., Barrios-Garcia, M. N., \& Bunn, W. (2012). The natives are restless, but not often and mostly when disturbed. Ecology, 93(3), 598-607.

Stevens, D. L., Jr., \& Olsen, A. R. (1999). Spatially restricted surveys over time for aquatic resources. Journal of Agricultural, Biological, and Environmental Statistics, 4, 415-428.

Stevens, D. L., Jr., \& Olsen, A. R. (2003). Variance estimation for spatially balanced samples of environmental resources. Environmetrics, 14, 593-610.

Stevens, D. L., Jr., \& Olsen, A. R. (2004). Spatially-balanced sampling of natural resources. Journal of American
Statistical Association, 99(465), 262-278. https://doi. org/10.1198/016214504000000250.

Stoddard, J. L., Herlihy, A. T., Peck, D. V., Hughes, R. M., Whittier, T. R., \& Tarquinio, E. (2008). A process for creating multimetric indices for large-scale aquatic surveys. Journal of North American Benthological Society, 27(4), 878-891.

Tecco, P. A., Díaz, S., Cabido, M., \& Urcelay, C. (2010). Functional traits of alien plants across contrasting climatic and land-use regimes: do aliens join the locals or try harder than them? Journal of Ecology, 98(1), 17-27. https://doi. org/10.1111/j.1365-2745.2009.01592.x.

Thuiller, W., Richardson, D. M., Rouget, M., Proches, S., \& Wilson, J. R. U. (2006). Interactions between environment, species traits, and human uses describe patterns of plant invasions. Ecology, 87(7), 1755-1769.

Uddin, M. N., Robinson, R. W., Buultjens, A., Al Harun, M. A. Y., \& Shampa, S. H. (2017). Role of allelopathy of Phragmites australis in its invasion processes. Journal of Experimental Marine Biology and Ecology, 486(Supplement C), 237-244. https://doi.org/10.1016/j.jembe.2016.10.016.

USACE (2014). National wetland plant list, version 3.2, US Army Corps of Engineers. https://www.wetland-plants.usace.army. mil

USDA-NRCS (2012). The PLANTS Database (http://plants.usda. gov, 23 January 2012).

USDA-NRCS (2013). The PLANTS Database (http://plants.usda. gov, October-November 2013).

USDA-NRCS (2014). The PLANTS Database (http://plants.usda. gov, 18 March 2014).

USEPA. (2009). National lakes assessment: a collaborative survey of the nation's lakes. EPA 841-R-09-001. Washington, D.C.: U.S. Environmental Protection Agency, Office of Water and Office of Research and Development.

USEPA. (2011a). National Wetland Condition Assessment: field operations manual. EPA/843/R10/001. Washington, D.C.: U.S. Environmental Protection Agency.

USEPA. (2011b). National Wetland Condition Assessment: laboratory operations manual. EPA-843-R-10-002. Washington, D.C.: U.S. Environmental Protection Agency.

USEPA. (2016a). National rivers and streams assessment 20082009 technical report (EPA/841/R-16/008). http:/www.epa. gov/national-aquatic-resource-surveys/nrsa. Washington, DC: U.S. Environmental Protection Agency. Office of Water and Office of Research and Development.

USEPA. (2016b). National rivers and streams assessment 2008 2009: a collaborative survey (EPA/841/R-16/007). http://www.epa.gov/national-aquatic-resource-surveys/nrsa. Washington, DC: U.S. Environmental Protection Agency. Office of Water and Office of Research and Development.

USEPA. (2016c). National Wetland Condition Assessment 2011: a collaborative survey of the nation's wetlands. EPA-843-R-15005. Available from: https://www.epa.gov/national-aquaticresource-surveys/national-wetland-condition-assessment2011-results. Washington, DC: US Environmental Protection Agency.

USEPA. (2016d). National Wetland Condition Assessment: 2011 technical report. EPA-843-R-15-006. Available from: https://www.epa.gov/national-aquatic-resourcesurveys/national-wetland-condition-assessment-2011results. Washington, DC: US Environmental Protection Agency. 
USEPA (2016e). U.S. Environmental Protection Agency. National aquatic resource surveys. National Wetland Condition Assessment 2011 (data and metadata files). Available from U.S. EPA website: http://www.epa.gov/national-aquaticresource-surveys/data-national-aquatic-resource-surveys.

USEPA (2016f). U.S. Environmental Protection Agency. National aquatic resource surveys. National Wetland Condition Assessment 2011 (NWCA 2011 disturbance gradient inputs - data (CSV) and NWCA 2011 disturbance gradient inputs metadata (TXT). [Specific metrics used in this paper were: metalHeavy_Index, HDIS_HIGH, HDIS_MED, B1H_AGR, B1H_HAB, B1H_HYD, B1H_IND, B1H_RESURB]. Available from U.S. EPA website: https://www.epa. gov/national-aquatic-resource-surveys/data-national-aquaticresource-surveys.

USEPA (2016g). U.S. Environmental Protection Agency. National aquatic resource surveys. National Wetland Condition Assessment 2011 (NWCA 2011 landscape metrics - data (CSV) and NWCA 2011 landscape metrics - metadata $(T X T)$ ). [Metrics used in the paper: ELEVMAX_200M, N L C D 200006 A G R I C P C T 1000 , NLCD2006_DEVEL̄OPEDPCT_1000, PM̄MEAN_PT] Available from U.S. EPA website: https://www.epa. gov/national-aquatic-resource-surveys/data-national-aquaticresource-surveys.

USEPA (2016h). U.S. Environmental Protection Agency. National aquatic resource surveys. National Wetland Condition Assessment 2011 (NWCA 2011 plant CC and native status values - data (CSV) and NWCA 2011 Plant $C C$ and native status values - metadata (TXT)). [Includes (for observed plant species) state-level trait information for: C-Values, Native Status Designations, and Disturbance Sensitivity Categories]. Available from U.S. EPA website: https:/www.epa.gov/national-aquatic-resource-surveys/datanational-aquatic-resource-surveys.

USEPA (2016i). U.S. Environmental Protection Agency. National aquatic resource surveys. National Wetland Condition Assessment 2011 (NWCA 2011 plant species cover and height - data (CSV) and NWCA 2011 plant species cover and height - metadata (TXT)). [Includes field data for observed plant species: identity, presence, cover, and height]. Available from U.S. EPA website: https://www.epa. gov/national-aquatic-resource-surveys/data-national-aquaticresource-surveys.

USEPA (2016j). U.S. Environmental Protection Agency. National aquatic resource surveys. National Wetland Condition Assessment 2011 (NWCA 2011 plant taxonomy and life history - data (CSV) and NWCA 2011 plant taxonomy and life history - metadata (TXT)). [Includes (for observed plant species) name and trait information: taxonomy, plant category, growth habit, and duration]. Available from U.S. EPA website: https://www.epa.gov/national-aquatic-resourcesurveys/data-national-aquatic-resource-surveys.

USEPA (2016k). U.S. Environmental Protection Agency. National aquatic resource surveys. National Wetland
Condition Assessment 2011 (NWCA 2011 plant wetland indicator status - data (CSV) and NWCA 2011 plant wetland indicator status - metadata (TXT)). [Includes regionally specific wetland indicator status for observed plant species]. Available from U.S. EPA website: https://www.epa. gov/national-aquatic-resource-surveys/data-national-aquaticresource-surveys.

USEPA (20161). U.S. Environmental Protection Agency. National aquatic resource surveys. National Wetland Condition Assessment 2011 (NWCA 2011 site information - data (CSV) and NWCA 2011 site information - metadata (TXT)). [Specific data used in this paper: UID, SITE_ID, NWCA_WETGRP, NWCA_ECO4, ECO_X_WETGRP, AGGR_ECO9_2015, WGT_11]. Available from U.S. EPA website: https://www.epa.gov/national-aquatic-resourcesurveys/data-national-aquatic-resource-surveys.

USEPA (2016m). U.S. Environmental Protection Agency. National aquatic resource surveys. National Wetland Condition Assessment 2011 (NWCA 2011 vegetation metrics - data (CSV) and NWCA 2011 vegetation metrics - metadata (TXT)). Available from U.S. EPA website: https://www.epa. gov/national-aquatic-resource-surveys/data-national-aquaticresource-surveys.

USGS (2006). National elevation dataset (NED). http://ned.usgs. gov. Date accessed: September 2013. U.S. Geological Survey.

Vilà, M., Espinar, J. L., Hejda, M., Hulme, P. E., Jarošík, V., Maron, J. L., Pergl, J., Schaffner, U., Sun, Y., \& Pyšek, P. (2011). Ecological impacts of invasive alien plants: a metaanalysis of their effects on species, communities and ecosystems. Ecology Letters, 14(7), 702-708. https://doi. org/10.1111/j.1461-0248.2011.01628.x.

Vitousek, P. M., D’Antonio, C. M., Loope, L. L., Rejmánek, M., \& Westbrooks, R. (1997). Introduced species: a significant component of human-caused global change. New Zealand Journal of Ecology, 21(1), 1-16.

Waggy, M. A. (2009). Solanum dulcamara. In: Fire effects information system, [online]. U.S. Department of Agriculture, Forest Service, Rocky Mountain Research Station, Fire Sciences Laboratory (Producer). Available: https://www.fs. fed.us/database/feis/plants/shrub/soldul/all.html Accessed 24 July 2018.

Weihe, P. E., \& Neely, R. K. (1997). The effects of shading on competition between purple loosestrife and broad-leaved cattail. Aquatic Botany, 59, 127-138.

Wentworth, T. R., Johnson, G. P., \& Kologiski, R. L. (1988). Designation of wetlands by weighted averages of vegetation data: a preliminary evaluation. Water Resources Bulletin, 24, 389-396.

Publisher's note Springer Nature remains neutral with regard to jurisdictional claims in published maps and institutional affiliations. 